Check for updates

Cite this: RSC Adv., 2019, 9, 12696

Received 16th January 2019

Accepted 26th March 2019

DOI: $10.1039 / c 9 r a 00375 d$

rsc.li/rsc-advances

\section{A magnetically recyclable superparamagnetic silica supported Pt nanocatalyst through a multi- carboxyl linker: synthesis, characterization, and applications in alkene hydrosilylation $\uparrow$}

\begin{abstract}
Laiming Li, Youxin Li, (D)* Jincong Yan, Hang Cao, Dongyun Shao and James J. Bao
To simplify separation procedures, improve the reusability and decrease the loss of Pt, two Pt catalysts anchored on superparamagnetic silica $\left(\mathrm{Fe}_{3} \mathrm{O}_{4} \mathrm{QSiO}_{2}-\mathrm{EDTA} \propto \mathrm{Pt}\right.$ and $\mathrm{Fe}_{3} \mathrm{O}_{4}\left(\mathrm{CSiO}_{2}-\mathrm{DTPA} @ \mathrm{Pt}\right)$ were prepared for the first time. The stable magnetic properties made them easily recyclable using a magnet rather than filtration, decantation or centrifugation. After 12 catalytic runs for both $30-50 \mathrm{~nm} \mathrm{Pt}$ catalysts, the yield of 1-heptylmethyldichlorosilane was still up to $90 \%$. The average loss of Pt in each reaction was only $0.87 \%$ for $\mathrm{Fe}_{3} \mathrm{O}_{4} \mathrm{aSiO}_{2}$-EDTA@Pt and $0.66 \%$ for $\mathrm{Fe}_{3} \mathrm{O}_{4} \mathrm{aSiO}_{2}-\mathrm{DTPA} @ \mathrm{Pt}$ owing to the strong interaction between $\mathrm{Pt}$ and carboxyl. The unprecedented activity and selectivity of the two Pt nanoparticle catalysts were observed in the hydrosilylation of alkenes. The turnover number in the reaction between 1-hexene and methyldichlorosilane using $5 \times 10^{-8} \mathrm{~mol}$ of the Pt approached 662733 for $\mathrm{Fe}_{3} \mathrm{O}_{4} \mathrm{aSiO}_{2}-\mathrm{EDTA} @ \mathrm{Pt}$ and 579947 for $\mathrm{Fe}_{3} \mathrm{O}_{4} \mathrm{aSiO}_{2}-\mathrm{DTPA} a \mathrm{Pt}$ over $12 \mathrm{~h}$. The corresponding hydrosilylation products in excellent yields were obtained when we employed a broad range of alkenes as substrates, including 5 isomerous hexenes and 14 important industry raw materials. $\mathrm{Fe}_{3} \mathrm{O}_{4}\left(\mathrm{aSiO}_{2}{ }^{-}\right.$ DTPA@Pt showed a better activity. They have potential for catalyzing more reactions and replacing the current homogeneous Pt catalysts in industry.
\end{abstract}

\section{Introduction}

Magnetic materials such as magnetite $\left(\mathrm{Fe}_{3} \mathrm{O}_{4}\right)$ and maghemite $\left(\gamma-\mathrm{Fe}_{2} \mathrm{O}_{3}\right)$ are widely utilized in various fields, such as highdensity data storage, chemical sensors, catalysts, drug delivery, biological assays, and electro photographic developers. ${ }^{1-5}$ Compared with traditional techniques such as filtration, decantation or centrifugation, magnetic materials could be easily separated from solution and re-dispersed through an external magnetic field, ${ }^{6}$ which overcomes time- and solventconsuming procedures. ${ }^{6}$ Magnetite $\mathrm{Fe}_{3} \mathrm{O}_{4}$, especially nano$\mathrm{Fe}_{3} \mathrm{O}_{4}$ possessing super paramagnetic behavior at a nanoparticle size with high surface area, is attractive for practical applications. ${ }^{7-10}$ An ongoing application of magnetic materials is to immobilize metal catalysts because efficient separation, recovery and recycling of the catalyst may enhance their lifetime and minimize their consumption to result in significant economical and environmental benefits. ${ }^{11-14}$

Tianjin Key Laboratory for Modern Drug Delivery and High-Efficiency, Collaborative Innovation Center of Chemical Science and Engineering, School of Pharmaceutical Science and Technology, Tianjin University, Room 412-8, Building No. 24, 92 Weijin Road, Nankai District, Tianjin 300037, China. E-mail: lyx@tju.edu.cn; Fax: +86-222789-2820; Tel: $+86-22-2789-2820$

$\dagger$ Electronic supplementary information (ESI) available. See DOI: $10.1039 / \mathrm{c} 9 \mathrm{ra} 00375 \mathrm{~d}$
Among these transition metal catalysts, such as copper $(\mathrm{Cu})$, platinum (Pt), palladium (Pd), rhodium (Rh), nickel $(\mathrm{Ni})$ or ruthenium $(\mathrm{Ru}),{ }^{15-20} \mathrm{Pt}$ is one of the most widely used owing to its unparalleled catalytic activity and mild reaction conditions in various fields, such as hydrosilylation, aldehyde oxidation, sulfuric acid decomposition. Although homogeneous Pt catalysts such as Speier's catalyst and the Karstedt's catalyst suffer from a number of drawbacks, like side reactions and low selectivity and reusability, there isn't efficient substitution in industry. The immobilization of platinum catalyst is a wise choice. Numerous researches were being reported on how to immobilize Pt on magnetic materials. ${ }^{21-26}$

Magnetic silica is used as an ideal inorganic support because of its merits, like magnetic property, easy modification, high biocompatibility, solvent compatibility, adsorption capacity, acid-base properties, and chemical and thermal stability when compared to other structures. ${ }^{27-29}$ A number of multi-carboxyl based affinity ligands, such as ethylenediaminetetraacetic acid (EDTA) and diethylenetriaminepentaacetic acid (DTPA), are well-known chelators for their strong metal-complexing property. ${ }^{30}$ Magnetic silica particles modified by EDTA or DTPA were widely used in industries including cleaning, the nuclear industry, pharmaceuticals, and the manufacturing of textile leather, rubber, and paper, etc. ${ }^{31-35}$ The immobilized Pt catalysts on silica gel through EDTA and DTPA were developed by our 
group. ${ }^{36,37}$ EDTA and DTPA showed a strong interaction with platinum, but the kinds of heterogeneous catalysts still need to reuse through centrifugation and $31 \% \mathrm{Pt}$ was loss after 13 recycles.

Here, we first time try to immobilize Pt catalysts through carboxyl ligands like EDTA or DTPA grafted onto the surface of magnetite silica $\left(\mathrm{Fe}_{3} \mathrm{O}_{4} @ \mathrm{SiO}_{2}\right.$-EDTA@Pt and $\mathrm{Fe}_{3} \mathrm{O}_{4} @ \mathrm{SiO}_{2}{ }^{-}$ DTPA@Pt) to simplify separation procedure, improve the reusability and decrease the loss of Pt. In addition, the two catalysts are applied first time in 4 isomerization-hydrosilylation and hydrosilylation of 14 compounds, which are important industry raw materials. These make the current two catalysts more valuable industry.

\section{Experimental section}

\subsection{Materials and reagents}

All chemicals were used as received without further purification. Iron chloride hexahydrate $\left(\mathrm{FeCl}_{3} \cdot 6 \mathrm{H}_{2} \mathrm{O},>99 \%\right)$ and ferrous chloride tetrahydrate $\left(\mathrm{FeCl}_{2} \cdot 4 \mathrm{H}_{2} \mathrm{O},>99 \%\right)$ were from Yuanli Chemical. $\gamma$-Aminopropyltrimethoxysilane (APTMS) was from Qufu Chenguang Chemical. Tetraethylorthosilicate (TEOS) was from Tianjin Kemiou Chemical Reagent. Ethylenediaminetetraacetic acid (EDTA), diethylenetriaminepentaacetic acid (DTPA), sodium silicate, ammonia solution (25\%), anhydrous pyridine, acetic anhydride, diethyl ether, hydrochloric acid $(\mathrm{HCl})$, toluene, acetone, ethanol, methanol, $n$ decane, i-propanol, $n$-butanol and $n$-hexanol were from Jiangtian Chemical Technology. Methyldichlorosilane was from Kaihua Synthetic. 1-Hexene, trans-2-hexene, cis-2-hexene, trans3-hexene and cis-3-hexene were form Tokyo Chemical Industry Co., Ltd. N,N-Dimethylacrylamide, 1,2-epoxy-4vinylcyclohexane, methyl methacrylate, butyl acrylate, ethane1,2-diyl bis(2-methylacrylate), crotonic acid ethyl ester and trans-2-hexenyl acetate were from Bid Pharmatech Ltd. 1,2Epoxy-7-octene, allyl glycidyl ether, 5-hexen-2-one, allylchloride and trans-2-hexen-1-yl phenylacetate were from Nanjin Shengbicheng Chemical Technology Co., Ltd. Cyclohexene and norbornylene were from Shanghai Macklin Biochemical Co., Ltd. $\mathrm{H}_{2} \mathrm{PtCl}_{6} \cdot 6 \mathrm{H}_{2} \mathrm{O}$ was from Tianjin Fengchuan Chemical Reagent Technologies. 1-Hexyl-methyldichlorosilane was from CNW Technologies. Deionized water was from Tianjin Yongyuan Distilled Water Manufacturing Center.

\subsection{Materials synthesis}

2.2.1. Preparation of $\mathrm{Fe}_{3} \mathrm{O}_{4}$ and $\mathrm{Fe}_{3} \mathrm{O}_{4} @ \mathrm{SiO}_{2}$. The magnetite $\mathrm{Fe}_{3} \mathrm{O}_{4}$ and $\mathrm{Fe}_{3} \mathrm{O}_{4} @ \mathrm{SiO}_{2}$ nanoparticles were prepared according to previous reported method with a minor modification. ${ }^{38-43}$ The magnetite $\mathrm{Fe}_{3} \mathrm{O}_{4}$ nanoparticles were prepared by chemical co-precipitation of ferric and ferrous ions in ammonium hydroxide solution. Briefly, under nitrogen protection, $0.04 \mathrm{~mol} \mathrm{FeCl}_{3} \cdot 6 \mathrm{H}_{2} \mathrm{O}$ and $0.02 \mathrm{~mol} \mathrm{FeCl} \cdot \cdot 4 \mathrm{H}_{2} \mathrm{O}$ were dissolved in distilled water with vigorous stirring at $80^{\circ} \mathrm{C}$ for $20 \mathrm{~min}$. After $15 \mathrm{~mL}$ ammonium hydroxide (25\% aqueous solution) was added to the solution, the color of the bulk solution turned from orange to black immediately. After $30 \mathrm{~min}$ of reaction, the black precipitate was collected from the reaction mixture by a powerful magnet and washed three times with distilled water before it was re-dispersed into a $100 \mathrm{~mL}$ distilled water to form a nanoparticle suspension of $c a .50 \mathrm{mg} \mathrm{mL} \mathrm{m}^{-1}$.

The magnetite $\mathrm{Fe}_{3} \mathrm{O}_{4} @ \mathrm{SiO}_{2}$ nanoparticles were prepared by two sol-gel approach. First, the surface of $\mathrm{Fe}_{3} \mathrm{O}_{4}$ nanoparticles was covered by silica layer $\left(\mathrm{SiO}_{2}\right.$ encapsulated $\mathrm{Fe}_{3} \mathrm{O}_{4}$ particles, $\mathrm{Fe}_{3} \mathrm{O}_{4} @ \mathrm{SiO}_{2}$ ). Briefly, sodium silicate was dissolved in deionized water in a glass beaker equipped with a mechanical stirrer and the $\mathrm{pH}$ was adjusted to $12-13$ by sodium hydroxide. $\mathrm{Fe}_{3} \mathrm{O}_{4}$ nanoparticles were added to the sodium silicate solution. The mixture was treated ultrasonically for $30 \mathrm{~min}$. Then, the temperature of the mixture was increased to $85^{\circ} \mathrm{C}$ and nitrogen gas was used to prevent the intrusion of oxygen. $2 \mathrm{M}$ hydrochloric acid was added dropwise to adjust $\mathrm{pH}$ value to 6.0. Then, the precipitates were washed several times with deionized water by magnetic decantation. The $\mathrm{Fe}_{3} \mathrm{O}_{4} @ \mathrm{SiO}_{2}$ was coated again to ensure that the desired amount of silica on all magnetite $\mathrm{Fe}_{3} \mathrm{O}_{4} \cdot{ }^{44,45}$ For this, $\mathrm{Fe}_{3} \mathrm{O}_{4} @ \mathrm{SiO}_{2}$ was re-dispersed in $100 \mathrm{~mL}$ methanol-water $(1: 1, \mathrm{v} / \mathrm{v})$ mixture and followed by the addition of $1 \mathrm{~mL}$ ammonium hydroxide (25\% aqueous solution). Then, $1 \mathrm{~mL}$ of TEOS was dissolved in $10 \mathrm{~mL}$ methanol and added dropwise to the mixture by gently stirring for $1 \mathrm{~h}$. The obtained nanoparticles $\left(\mathrm{Fe}_{3} \mathrm{O}_{4} @ \mathrm{SiO}_{2}\right)$ were collected by magnet and washed several times with distilled water and ethanol. Finally, the nanoparticles were dried at room temperature under vacuum and brown yellow solid was observed.

2.2.2. Preparation of amino-magnetic silica $\left(\mathrm{Fe}_{3} \mathrm{O}_{4} @ \mathrm{SiO}_{2}-\right.$ AP). It was prepared according to previous reported method. ${ }^{46}$ Ten grams as-made magnetic silica nanoparticles were ultrasonically dispersed in $100 \mathrm{~mL}$ distilled toluene for $30 \mathrm{~min}$. Then, it was transferred into a $250 \mathrm{~mL}$ three-necked flask equipped with a mechanical stirrer. 3-Aminopropyltrimethoxysilane $(20 \mathrm{~mL})$ was added into this mixture. The temperature was kept at $110^{\circ} \mathrm{C}$ with continuous stirring for $24 \mathrm{~h}$. The resulting nanoparticles were separated by magnet, washed with methanol for several times and then dried at $60^{\circ} \mathrm{C}$ under vacuum for $12 \mathrm{~h}$. The product was referred to as $\mathrm{Fe}_{3}$ $\mathrm{O}_{4} @ \mathrm{SiO}_{2}$-AP.

2.2.3. Preparation of multi-carboxyl magnetic silica $\left(\mathrm{Fe}_{3^{-}}\right.$ $\mathrm{O}_{4} @ \mathrm{SiO}_{2}$-EDTA and $\mathrm{Fe}_{3} \mathrm{O}_{4} @ \mathrm{SiO}_{2}$-DTPA). The preparation of EDTA or DTPA dianhydride was done according to a previous reported method with minor modification. ${ }^{47}$ EDTA or DTPA was suspended in pyridine followed by the addition of acetic anhydride. The mixture was stirred at $65^{\circ} \mathrm{C}$ for $24 \mathrm{~h}$. The product was filtered, washed with acetic anhydride and diethyl ether, and dried in an oven for $6 \mathrm{~h}$. Next, $5 \mathrm{~g}$ of $\mathrm{Fe}_{3} \mathrm{O}_{4} @ \mathrm{SiO}_{2}-\mathrm{AP}$ was suspended in $100 \mathrm{~mL}$ mixture solution of ethanol and acetic acid $(1: 1, \mathrm{v} / \mathrm{v})$. After the addition of $25 \mathrm{~g}$ of EDTA dianhydride or $30 \mathrm{~g}$ DTPA dianhydride, the mixture was kept at $80{ }^{\circ} \mathrm{C}$ for $24 \mathrm{~h}$ to allow the amino groups on the silica gel to react with the carboxyl groups ${ }^{48,49}$ Finally the yellowish-brown product was separated by magnet and washed with $4 \mathrm{M}$ ammonia water solution to remove unreacted EDTA or DTPA. ${ }^{50}$ Then products were washed again with ethanol/acetic acid $(1: 1, \mathrm{v} / \mathrm{v})$, water and methanol sequentially. ${ }^{51}$ The multi-carboxyl modified 
magnetic silica gels $\left(\mathrm{Fe}_{3} \mathrm{O}_{4} @ \mathrm{SiO}_{2}\right.$-EDTA or $\mathrm{Fe}_{3} \mathrm{O}_{4} @ \mathrm{SiO}_{2}$-DTPA) were dried in an oven at $90{ }^{\circ} \mathrm{C}$ for $8 \mathrm{~h}$.

2.2.4. Preparation of catalysts. The above multi-carboxyl modified magnetic silica gels $\left(\mathrm{Fe}_{3} \mathrm{O}_{4} @ \mathrm{SiO}_{2}\right.$-EDTA or $\mathrm{Fe}_{3} \mathrm{O}_{4}$ @$\mathrm{SiO}_{2}$-DTPA) (1.51 g) were added to $50 \mathrm{~mL} \mathrm{H}_{2} \mathrm{PtCl}_{6} \cdot 6 \mathrm{H}_{2} \mathrm{O}(0.20 \mathrm{~g})$ ethanol solution. The mixture was carried out in a reflux at $80^{\circ} \mathrm{C}$ under nitrogen atmosphere and stirred for $9 \mathrm{~h}$. The solid product was filtered by a magnet and washed with ethanol successively and dried at $70{ }^{\circ} \mathrm{C}$ for $3 \mathrm{~h}$. The light yellow platinum complex was obtained, which were denoted as $\mathrm{Fe}_{3} \mathrm{O}_{4} @ \mathrm{SiO}_{2}$ EDTA@Pt and $\mathrm{Fe}_{3} \mathrm{O}_{4} @ \mathrm{SiO}_{2}$-DTPA@Pt. The process was schematically illustrated in Fig. 1.

\subsection{Characterization of the catalysts}

The crystal lattice structure of the magnetic intermediates $\left(\mathrm{Fe}_{3} \mathrm{O}_{4}, \mathrm{Fe}_{3} \mathrm{O}_{4} @ \mathrm{SiO}_{2}, \mathrm{Fe}_{3} \mathrm{O}_{4} @ \mathrm{SiO}_{2}-\mathrm{AP}\right)$, and products $\left(\mathrm{Fe}_{3} \mathrm{O}_{4} @\right.$ @$\mathrm{SiO}_{2}$-EDTA@Pt, $\mathrm{Fe}_{3} \mathrm{O}_{4} @ \mathrm{SiO}_{2}$-DTPA@Pt) were identified by XRD, in the $2 \theta$ range of $10-90^{\circ}$ at a scan speed of $4^{\circ} \min ^{-1}$, using a Rigaku D/MAX-2500 diffractometer with $\mathrm{Cu}-\mathrm{K} \alpha$ radiation $(\lambda=$ $0.1540 \mathrm{~nm}$ ). Particle sizes of the catalysts were studied using a JEOL JEM-2100F apparatus with an accelerating voltage of 200 $\mathrm{kV}$. TEM of $\mathrm{Fe}_{3} \mathrm{O}_{4} @ \mathrm{SiO}_{2}-\mathrm{EDTA} @ \mathrm{Pt}, \mathrm{Fe}_{3} \mathrm{O}_{4} @ \mathrm{SiO}_{2}$-DTPA@Pt were prepared by placing a drop containing the nanoparticles in a coated carbon grid. The morphology of the catalysts was investigated using a Hitachi S2800 SEM. The EDS analysis, which was simultaneously performed during the SEM examinations, was conducted to confirm the element distribution on the surface of adsorbents. FT-IR spectra were taken in $\mathrm{KBr}$ pressed pellets on a TENSOR 27 Spectrometer. EA was used to measure the nitrogen content in the materials on an Elementar Vario Micro cube. The thermal stabilities were measured by TGA employing a NETZSCH STA 409 TG-DTA under a dynamic nitrogen atmosphere at a heating rate of $10{ }^{\circ} \mathrm{C} \mathrm{min}^{-1}$. The magnetization and hysteresis loops were measured at room temperature by a LDJ9600 VSM. The BET measurement was carried out on a Quantachrome NOVA 1000 system at liquid- $\mathrm{N}_{2}$ temperature.

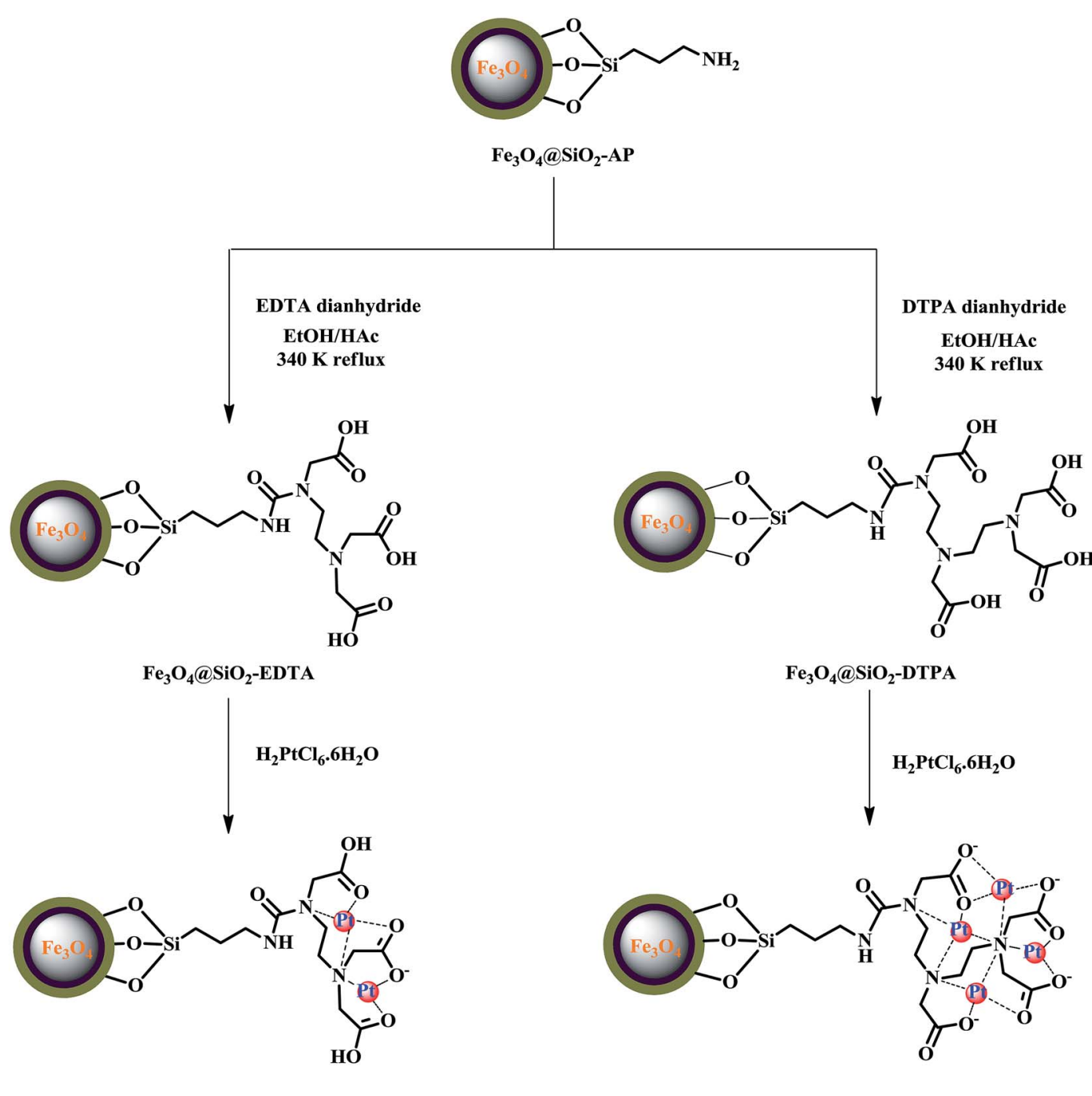

$\mathrm{Fe}_{3} \mathrm{O}_{4} @ \mathrm{SiO}_{2}$-EDTA@Pt

$\mathrm{Fe}_{3} \mathrm{O}_{4} @ \mathrm{SiO}_{2}$-DTPA@Pt

Fig. 1 Preparation of $\mathrm{Fe}_{3} \mathrm{O}_{4} \mathrm{aSiO}_{2}-\mathrm{EDTA} @ \mathrm{Pt}$ and $\mathrm{Fe}_{3} \mathrm{O}_{4} \mathrm{aSiO}_{2}-\mathrm{DTPA} a$ Pt catalysts. 


\subsection{Catalytic alkene hydrosilylation}

In a general procedure, hydrosilylation was carried out in a $50 \mathrm{~mL}$ round-bottomed tube equipped with a homemade reflux condenser to the upper of which a heating system was attached. An appropriate amount of alkene and platinum magnetic complex were stirred at a specific reaction temperature for $30 \mathrm{~min}$ before $15 \mathrm{mmol}$ methyldichlorosilane was added. The structure and yield of hydrosilylation products were determined based on calibration curves of standards. The catalyst was collected by simple magnetic separation and reused in subsequent runs without any treatment. All hydrosilylation products were characterized by comparing their spectra and physical parameters with authentic samples. The reaction product was quantified by gas chromatography (GC) and the structures of products were identified by nuclear magnetic resonance (NMR). GC equipped with a flame ionization detector (FID) (Wuhan Trustworthy Technology, China) and a long capillary column $(30 \mathrm{~m} \times 0.25 \mathrm{~mm} \times 0.25 \mu \mathrm{m})$ coated by $5 \%$ phenyl and $95 \%$ methyl polysiloxane. Injector and detector temperature was $260{ }^{\circ} \mathrm{C}$, carrier gas was nitrogen, injection volume at $0.8 \mu \mathrm{L}$, temperature programme: the column was kept at $60{ }^{\circ} \mathrm{C}$ for $3 \mathrm{~min}$, then heated to $260^{\circ} \mathrm{C}$ at a rate of $10^{\circ} \mathrm{C} \mathrm{min}{ }^{-1}$. ${ }^{1} \mathrm{H}$ NMR spectra were recorded on a Bruker AC-P400 (400 MHz) spectrometer in $\mathrm{CDCl}_{3}$ as solvent.

\section{Results and discussion}

\subsection{Synthesis}

In the synthetic procedures described earlier, magnetite $\mathrm{Fe}_{3} \mathrm{O}_{4}$ nanoparticles were prepared by the co-precipitation method from ferrous and ferric ion solutions at a mol ratio of $1: 2$. The magnetic nanoparticles have extensive hydroxyl groups on its surface when contacted with aqueous phase. ${ }^{52}$ Silicic acid as silica precursors encapsulated the $\mathrm{Fe}_{3} \mathrm{O}_{4}$ nanoparticles by two sol-gel approaches. First silicate acid layer was formed gradually from sodium silicate solution by dropwise addition of hydrochloric acid. The second silicate acid layer was formed by dropwise addition of TEOS solution. However, the TEOS is nonpolar in nature and it is necessary to use organic reagent like methanol as a mutual solvent to make TEOS and water miscible. Subsequently, the silanol groups $(\mathrm{Si}-\mathrm{OH})$ on the surface are transformed into siloxane bonds ( $\mathrm{Si}-\mathrm{O}-\mathrm{Si}$ ) via the condensation reaction and the silica coating is formed. ${ }^{53}$ Notably, the introduction of a dense silica coating on the magnetic nanoparticles is necessary for this study. It protects the magnetic $\mathrm{Fe}_{3} \mathrm{O}_{4}$ from oxidation and provides the surface charges needed to prevent aggregation in the subsequent condensation reactions and practical applications. The silanol groups change the surface properties making it easier and more effective to perform surface modification with organic silane molecules.

Before being modified by EDTA or DTPA group, the magnetic silica nanoparticles were functionalized with APTMS, which acted as an auto-catalyst. Those amino groups on the magnetic silica surface enable the magnetic silica materials to be functionalized with EDTA and DTPA by grafting the corresponding anhydrides on those amino groups. The EDTA or DTPA groups, in turn, serve as a new matrix to immobilize metallic Pt. The chemical structures of the resulting product were depicted in Fig. 1. The multi-carboxyl functionalized magnetic silica materials were found to be a yellow powder with an excellent shelf life. These magnetite nanoparticles functionalized with EDTA or DTPA will be referred to as $\mathrm{Fe}_{3} \mathrm{O}_{4} @ \mathrm{SiO}_{2}$-EDTA@Pt and $\mathrm{Fe}_{3}$ $\mathrm{O}_{4} @ \mathrm{SiO}_{2}$-DTPA@Pt.

\subsection{Characterization}

The data from AAS analysis indicated the amounts of Pt in $\mathrm{Fe}_{3} \mathrm{O}_{4} @ \mathrm{SiO}_{2}$-EDTA@Pt and $\mathrm{Fe}_{3} \mathrm{O}_{4} @ \mathrm{SiO}_{2}$-DTPA@Pt were 173.80 and $192.77 \mu \mathrm{mol} \mathrm{g}^{-1}$, respectively. As a comparison, Pt was also immobilized on $\mathrm{Fe}_{3} \mathrm{O}_{4} @ \mathrm{SiO}_{2}-\mathrm{AP}$ and $\mathrm{Fe}_{3} \mathrm{O}_{4} @ \mathrm{SiO}_{2}$, which had only 33.40 and $0.10 \mu \mathrm{mol} \mathrm{g}{ }^{-1}$ of Pt, respectively. It means the interaction between $\mathrm{Pt}$ and carboxyl is stronger than amino group, which is benefit to the immobilization and stability of Pt.

Morphology of the two novel catalysts was characterized by SEM, EDS and TEM (Fig. 2). Results showed that the dried power of $\mathrm{Fe}_{3} \mathrm{O}_{4} @ \mathrm{SiO}_{2}$-EDTA@Pt and $\mathrm{Fe}_{3} \mathrm{O}_{4} @ \mathrm{SiO}_{2}$-DTPA@Pt nanoparticles had an irregular surface with sharp edge and slight agglomeration, which could be dispersed well in solution. The presence of $\mathrm{Si}, \mathrm{O}$ and $\mathrm{Fe}$ signals in the EDS pattern confirmed that $\mathrm{Fe}_{3} \mathrm{O}_{4}$ was successfully mixed with silica. The higher intensity of $\mathrm{Si}$ peak compared with that of $\mathrm{Fe}$ peak showed that the $\mathrm{Fe}_{3} \mathrm{O}_{4}$ nanoparticles were coated by $\mathrm{SiO}_{2}$. The collected process by a magnet avoids the $\mathrm{SiO}_{2}$ nanoparticles without $\mathrm{Fe}_{3} \mathrm{O}_{4}$. The EDS analysis results also confirmed the elemental composition of the nanoparticles and the existence of Pt in the prepared nanoparticle catalysts. Through second robust sol-gel approach, the high magnification TEM images revealed that the $\mathrm{Fe}_{3} \mathrm{O}_{4} @ \mathrm{SiO}_{2}$-EDTA@Pt and $\mathrm{Fe}_{3} \mathrm{O}_{4} @ \mathrm{SiO}_{2}$ DTPA@Pt particles obtained were uniform with a diameter of about 30-50 nm. Each magnetic particle was composed of dark magnetic $\mathrm{Fe}_{3} \mathrm{O}_{4}$ nanoparticles of about 10-15 nm diameter. Even further, it clearly showed that those dark magnetic particles were coated with a light-gray $\mathrm{SiO}_{2}$ layer with a thickness of around $15 \mathrm{~nm}$.

The XRD patterns of $\mathrm{Fe}_{3} \mathrm{O}_{4}, \mathrm{Fe}_{3} \mathrm{O}_{4} @ \mathrm{SiO}_{2}, \mathrm{Fe}_{3} \mathrm{O}_{4} @ \mathrm{SiO}_{2}-\mathrm{AP}$, $\mathrm{Fe}_{3} \mathrm{O}_{4} @ \mathrm{SiO}_{2}$-EDTA@Pt and $\mathrm{Fe}_{3} \mathrm{O}_{4} @ \mathrm{SiO}_{2}$-DTPA@Pt nanoparticles were shown in Fig. 3. It showed typical X-ray diffraction patterns of $\mathrm{Fe}_{3} \mathrm{O}_{4} \cdot{ }^{54}$ The characteristic diffraction peaks appeared in $\mathrm{Fe}_{3} \mathrm{O}_{4}$ at $30.1^{\circ}, 35.5^{\circ}, 43.3^{\circ}, 54.3^{\circ}, 57.3^{\circ}$ and $62.6^{\circ}$ could be assigned to the planes of $\mathrm{Fe}_{3} \mathrm{O}_{4}$ (JCPDS No. 19629), respectively. These characteristic diffraction peaks were observed in $\mathrm{Fe}_{3} \mathrm{O}_{4} @ \mathrm{SiO}_{2}, \quad \mathrm{Fe}_{3} \mathrm{O}_{4} @ \mathrm{SiO}_{2}-\mathrm{AP}, \quad \mathrm{Fe}_{3} \mathrm{O}_{4} @ \mathrm{SiO}_{2}$ EDTA@Pt and $\mathrm{Fe}_{3} \mathrm{O}_{4} @ \mathrm{SiO}_{2}$-DTPA@Pt nanoparticles which indicated that $\mathrm{Fe}_{3} \mathrm{O}_{4}$ was existent in all synthesized samples and the whole preparation processes did not result in the phase change of $\mathrm{Fe}_{3} \mathrm{O}_{4}$. The obvious characteristic peak of Pt wasn't observed in $\mathrm{Fe}_{3} \mathrm{O}_{4} @ \mathrm{SiO}_{2}$-EDTA@Pt and $\mathrm{Fe}_{3} \mathrm{O}_{4} @ \mathrm{SiO}_{2}$-DTPA@Pt, which may indicate that the amount of Pt was low or the Pt particles were highly dispersed on the surface of support. ${ }^{55}$

In order to confirm properties of the surface of composite nanoparticles, the molecular structure of the different composites was characterized using FT-IR spectra (Fig. 4.). The typical absorption peak for $\mathrm{Fe}_{3} \mathrm{O}_{4}$ at 635 and $576 \mathrm{~cm}^{-1}$ was 

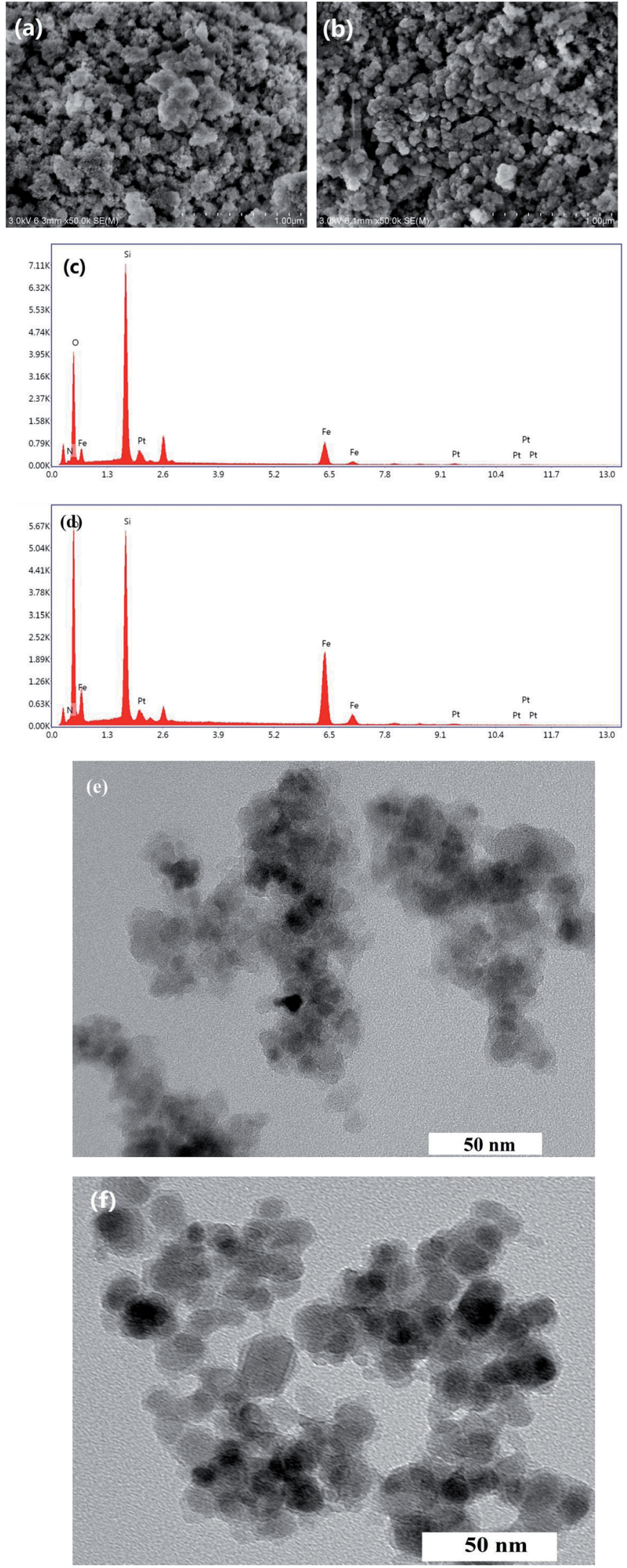

Fig. 2 SEM micrographs of (a) $\mathrm{Fe}_{3} \mathrm{O}_{4} \mathrm{CSiO}_{2}$-EDTACPt and (b) $\mathrm{Fe}_{3}-$ $\mathrm{O}_{4} \mathrm{aSiO}_{2}$-DTPA@Pt, EDS of (c) $\mathrm{Fe}_{3} \mathrm{O}_{4} \mathrm{aSiO}_{2}$-EDTA@Pt and (d) $\mathrm{Fe}_{3}-$ $\mathrm{O}_{4} \mathrm{aSiO}_{2}$-DTPA@Pt, TEM micrographs of (e) $\mathrm{Fe}_{3} \mathrm{O}_{4} \mathrm{aSiO}_{2}$-EDTA@Pt and (f) $\mathrm{Fe}_{3} \mathrm{O}_{4} @ \mathrm{aSiO}_{2}$-DTPA@Pt. attributed to the stretching vibration of $\mathrm{Fe}-\mathrm{O}$ bond. The typical peaks of $\mathrm{Fe}_{3} \mathrm{O}_{4}$ were observed in all of spectra, which further confirmed $\mathrm{Fe}_{3} \mathrm{O}_{4}$ nanoparticles existed in all of intermediates and products. Whereas the gradual decrease of peak signals indicated the $\mathrm{Fe}_{3} \mathrm{O}_{4}$ nanoparticles were at core of $\mathrm{Fe}_{3} \mathrm{O}_{4} @ \mathrm{SiO}_{2}$, $\mathrm{Fe}_{3} \mathrm{O}_{4} @ \mathrm{SiO}_{2}-\mathrm{AP}, \mathrm{Fe}_{3} \mathrm{O}_{4} @ \mathrm{SiO}_{2}$-EDTA, $\mathrm{Fe}_{3} \mathrm{O}_{4} @ \mathrm{SiO}_{2}$-EDTA@Pt, $\mathrm{Fe}_{3} \mathrm{O}_{4} @ \mathrm{SiO}_{2}$-DTPA and $\mathrm{Fe}_{3} \mathrm{O}_{4} @ \mathrm{SiO}_{2}$-DTPA@Pt. For $\mathrm{Fe}_{3} \mathrm{O}_{4} @$ @$\mathrm{SiO}_{2}$, a new board absorption peak at $1092 \mathrm{~cm}^{-1}$ resulted from $\mathrm{Si}-\mathrm{O}-\mathrm{Si}$ antisymmetric stretching vibration of silica layer, which verified the successful coating of silica layers onto $\mathrm{Fe}_{3} \mathrm{O}_{4}{ }^{56,57}$ The peak around $1627 \mathrm{~cm}^{-1}$ was attributed to the absorbed water on the silica shell or the silanol group of the silica. ${ }^{58}$ The characteristic absorption band at $3422 \mathrm{~cm}^{-1}$ was from the stretching vibrations of hydroxyl groups. These peaks from $\mathrm{Fe}_{3} \mathrm{O}_{4} @ \mathrm{SiO}_{2}$ were also observed in $\mathrm{Fe}_{3} \mathrm{O}_{4} @ \mathrm{SiO}_{2}-\mathrm{AP}, \mathrm{Fe}_{3} \mathrm{O}_{4} @$ $\mathrm{SiO}_{2}$-EDTA, $\mathrm{Fe}_{3} \mathrm{O}_{4} @ \mathrm{SiO}_{2}$-DTPA, $\mathrm{Fe}_{3} \mathrm{O}_{4} @ \mathrm{SiO}_{2}$-EDTA@Pt and $\mathrm{Fe}_{3} \mathrm{O}_{4} @ \mathrm{SiO}_{2}$-DTPA@Pt. After the functionalization of $\mathrm{Fe}_{3} \mathrm{O}_{4} @$ $\mathrm{SiO}_{2}$ with APTMS, the new absorption peaks at 2925 and $2858 \mathrm{~cm}^{-1}$ represented the symmetric vibrations of aliphatic $\mathrm{C}-\mathrm{H}$ stretching of the methylene group for silane coupling agent, which indicated that amino group was successfully grafted onto the surface of $\mathrm{Fe}_{3} \mathrm{O}_{4} @ \mathrm{SiO}_{2}$. After grafting multicarboxyl groups, the strong characteristic absorption band appeared at 1733 and $1404 \mathrm{~cm}^{-1}$ could be assigned to $\mathrm{C}=\mathrm{O}$ and $\mathrm{C}-\mathrm{O}$ stretching vibration of the - $\mathrm{COO}-$ group, which indicated the formation of carboxylic groups (EDTA and DTPA) on the surface of the $\mathrm{Fe}_{3} \mathrm{O}_{4} @ \mathrm{SiO}_{2}-\mathrm{AP}^{59}$ As a result of the presence of large quantities of metallic Pt on the surface of the nanoparticles, the decrease in vibration of $\mathrm{C}=\mathrm{O}$ and $\mathrm{C}-\mathrm{O}$ suggests that the carboxyl group on the surface of the functional magnetic silica have coordinated with platinum, signifying the immobilization of platinum complex on the $\mathrm{Fe}_{3} \mathrm{O}_{4} @ \mathrm{SiO}_{2}$-EDTA and $\mathrm{Fe}_{3} \mathrm{O}_{4} @ \mathrm{SiO}_{2}$-DTPA surface.

XPS was used to further characterize the above catalysts (Fig. 5.). XPS results showed distinct Fe, O, N, C, Si and Pt peaks from the two novel nanoparticles (Fig. 5a). The detail XPS data for $\mathrm{Fe}_{3} \mathrm{O}_{4} @ \mathrm{SiO}_{2}-\mathrm{AP}, \quad \mathrm{Fe}_{3} \mathrm{O}_{4} @ \mathrm{SiO}_{2}$-EDTA@Pt, $\mathrm{Fe}_{3} \mathrm{O}_{4} @ \mathrm{SiO}_{2}-$ DTPA@Pt and $\mathrm{H}_{2} \mathrm{PtCl}_{6} \cdot 6 \mathrm{H}_{2} \mathrm{O}$ were listed in Table 1. It revealed that the binding energies of $\mathrm{Si} 2 \mathrm{p}$ and $\mathrm{O}$ 1s in $\mathrm{Fe}_{3} \mathrm{O}_{4} @ \mathrm{SiO}_{2}-$ EDTA@Pt and $\mathrm{Fe}_{3} \mathrm{O}_{4} @ \mathrm{SiO}_{2}$-DTPA@Pt were similar to those of $\mathrm{Fe}_{3} \mathrm{O}_{4} @ \mathrm{SiO}_{2}$-AP. The banding energy of $\mathrm{Cl} 2 \mathrm{p}$ in $\mathrm{Fe}_{3} \mathrm{O}_{4} @ \mathrm{SiO}_{2}-$ EDTA@Pt and $\mathrm{Fe}_{3} \mathrm{O}_{4} @ \mathrm{SiO}_{2}$-DTPA@Pt was similar to that of $\mathrm{H}_{2} \mathrm{PtCl}_{6} \cdot 6 \mathrm{H}_{2} \mathrm{O}$. It was noteworthy that the banding energy of Pt 4f7/2 in $\mathrm{Fe}_{3} \mathrm{O}_{4} @ \mathrm{SiO}_{2}$-EDTA@Pt and $\mathrm{Fe}_{3} \mathrm{O}_{4} @ \mathrm{SiO}_{2}$-DTPA@Pt was 3-5 eV more than that in $\mathrm{H}_{2} \mathrm{PtCl}_{6} \cdot 6 \mathrm{H}_{2} \mathrm{O}$. It could be summarized that electron donation from carboxyl group to $\mathrm{Pt}$ to form the coordination bond between carboxyl and $\mathrm{Pt}$ in $\mathrm{Fe}_{3} \mathrm{O}_{4} @ \mathrm{SiO}_{2^{-}}$ EDTA@Pt and $\mathrm{Fe}_{3} \mathrm{O}_{4} @ \mathrm{SiO}_{2}$-DTPA@Pt, which was also consistent with the FT-IR results. The Pt $4 \mathrm{f}$ XPS spectra contain two peaks corresponding to $\mathrm{Pt} 4 \mathrm{f} 7 / 2$ and $4 \mathrm{f} 5 / 2$ states from the spinorbital splitting and each peak was de-convoluted with $\mathrm{Pt}(0)$,

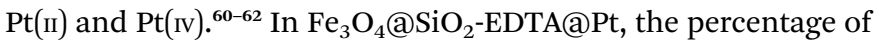
$\mathrm{Pt}^{4+}, \mathrm{Pt}^{2+}$ and $\mathrm{Pt}^{0}$ peaks were $28.9,46.5$ and $24.6 \%$, respectively. In $\mathrm{Fe}_{3} \mathrm{O}_{4} @ \mathrm{SiO}_{2}$-DTPA@Pt, the ratio of $\mathrm{Pt}^{2+}(50.3 \%)$ and $\mathrm{Pt}^{0}$ (26.4\%) were higher than that of $\mathrm{Fe}_{3} \mathrm{O}_{4} @ \mathrm{SiO}_{2}$-EDTA@Pt, whereas the $\mathrm{Pt}^{4+}$ decreased to $23.3 \%$. Results indicated the $\mathrm{Pt}^{2+}$ and $\mathrm{Pt}^{0}$ were predominant species that may be corresponding to 


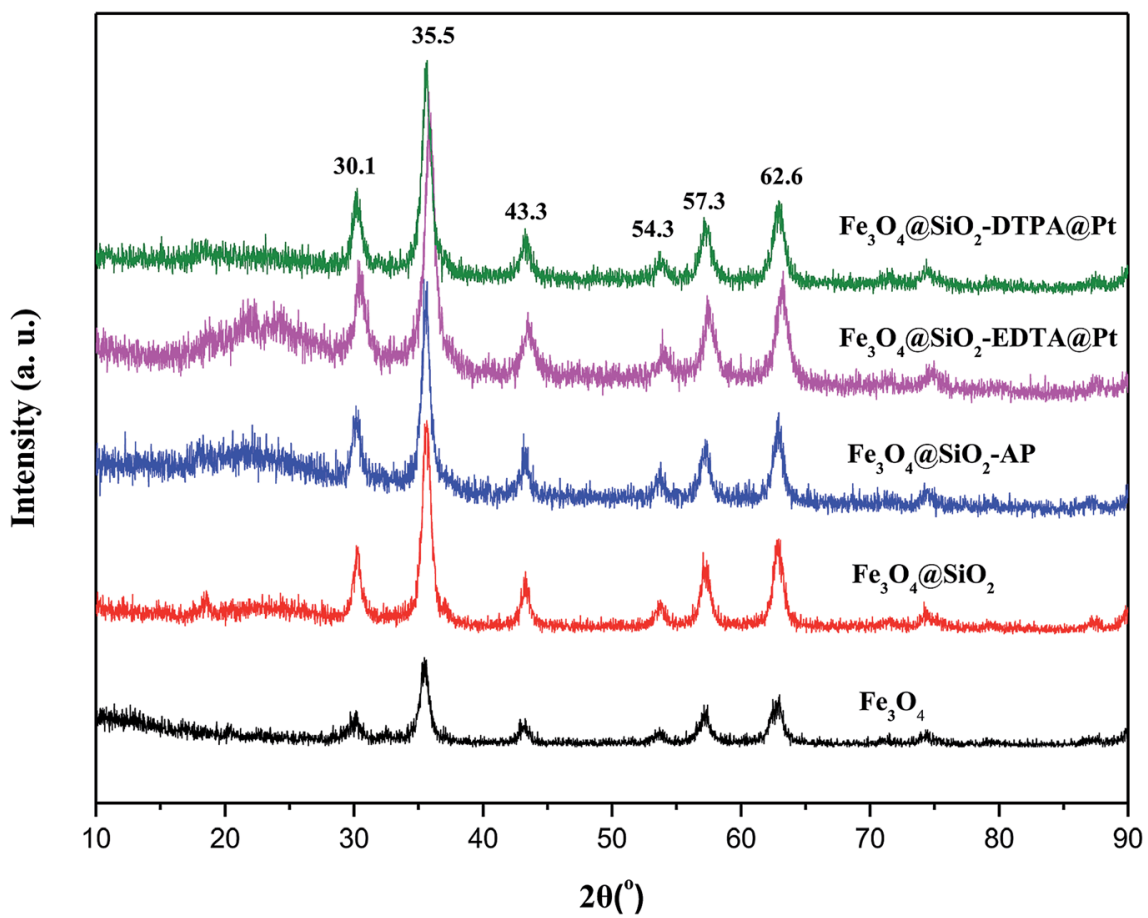

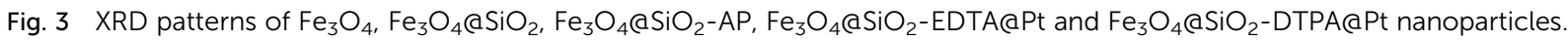

good catalytic activity and might be produced on the catalyst surface through passivation process during the sample preparation.

BET analysis showed another important characteristic of the Pt catalysts. Fig. 6a shows the nitrogen adsorption isotherms and pore-size distribution of $\mathrm{Fe}_{3} \mathrm{O}_{4} @ \mathrm{SiO}_{2}$-EDTA@Pt and $\mathrm{Fe}_{3}$ $\mathrm{O}_{4} @ \mathrm{SiO}_{2}$-DTPA@Pt catalysts. Both of two samples showed type III isotherms with type H3 hysteresis loops which is related to the slit-like pores because of aggregation of particles. ${ }^{63}$ When we dispersed these nanoparticles in aqueous solution and

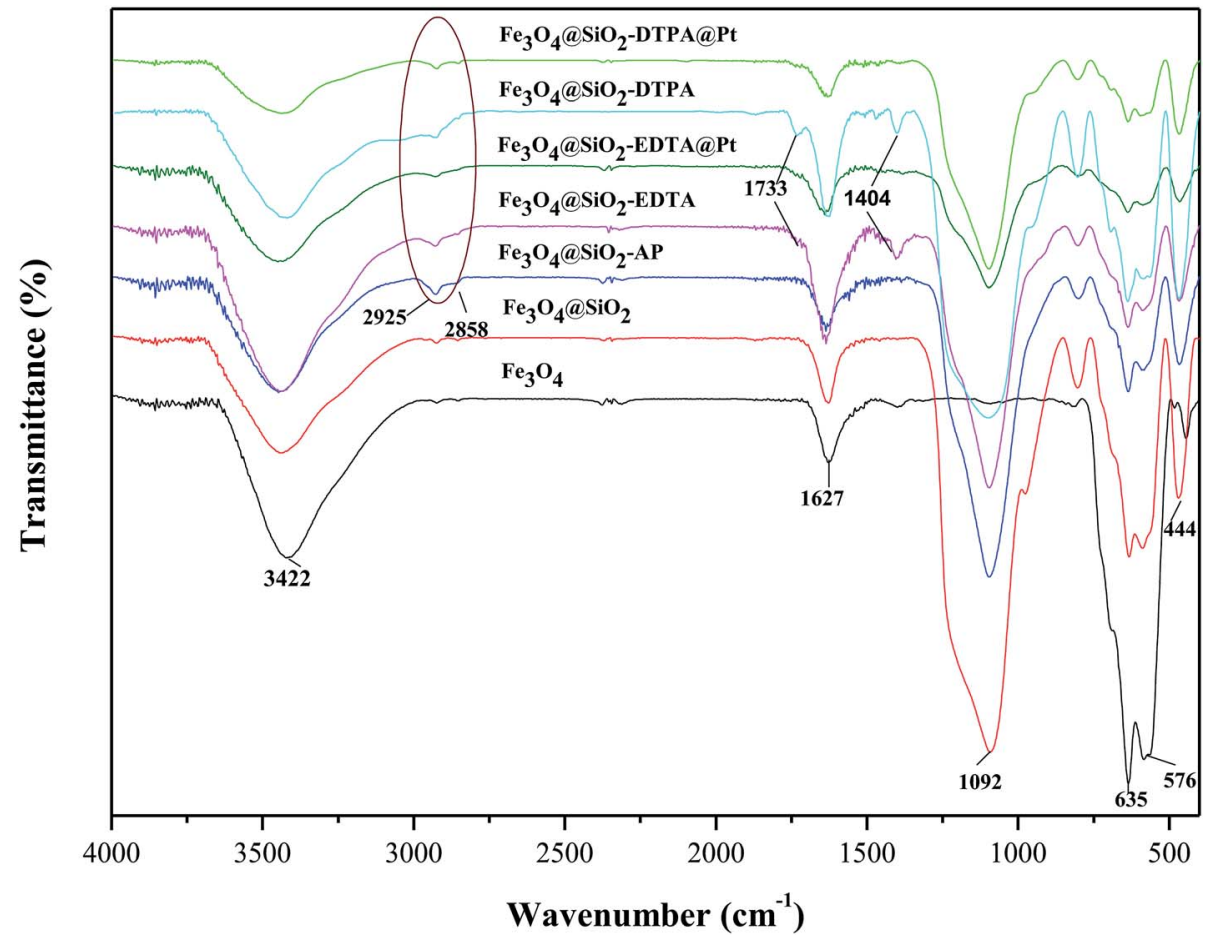

Fig. 4 FT-IR spectra of $\mathrm{Fe}_{3} \mathrm{O}_{4}, \mathrm{Fe}_{3} \mathrm{O}_{4} \mathrm{aSiO}_{2}, \mathrm{Fe}_{3} \mathrm{O}_{4} \mathrm{aSiO}_{2}-\mathrm{AP}, \mathrm{Fe}_{3} \mathrm{O}_{4} \mathrm{aSiO}_{2}-\mathrm{EDTA}, \mathrm{Fe}_{3} \mathrm{O}_{4} \mathrm{aSiO}_{2}-\mathrm{EDTA} \mathrm{aPt}, \mathrm{Fe}_{3} \mathrm{O}_{4} \mathrm{aSiO}_{2}-\mathrm{DTPA}$, and Fe $3 \mathrm{O}_{4} \mathrm{aSiO}_{2}-$ DTPA@Pt nanoparticles. 

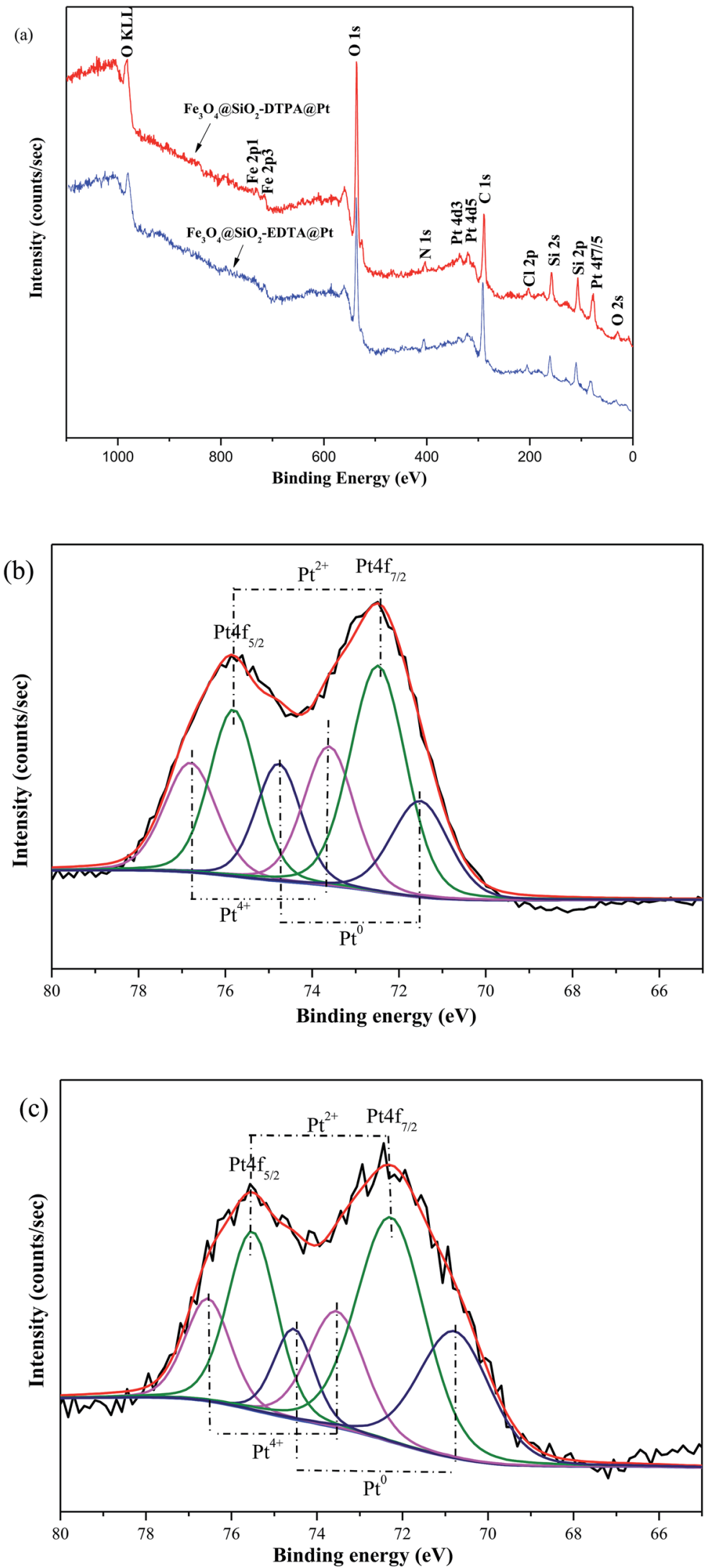

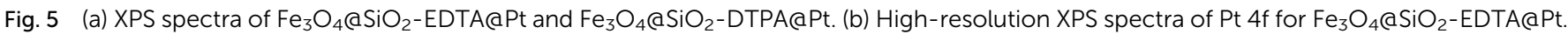
(c) High-resolution XPS spectra of Pt $4 \mathrm{f}$ for $\mathrm{Fe}_{3} \mathrm{O}_{4} \mathrm{QSiO}_{2}$-DTPA@Pt. 
Table 1 XPS data for $\mathrm{Fe}_{3} \mathrm{O}_{4} \mathrm{aSiO}_{2}$-EDTA@Pt and $\mathrm{Fe}_{3} \mathrm{O}_{4} \mathrm{aSiO}_{2}-$ DTPA@Pt, $\mathrm{Fe}_{3} \mathrm{O}_{4}\left(\mathrm{aSiO}_{2}-\mathrm{AP}\right.$ and $\mathrm{H}_{2} \mathrm{PtCl}_{6} \cdot 6 \mathrm{H}_{2} \mathrm{O}(\mathrm{eV})^{a}$

\begin{tabular}{llllll}
\hline Samples & Pt 4f7/2 & Si 2p & N 1s & O 1s & Cl 2p \\
\hline $\mathrm{Fe}_{3} \mathrm{O}_{4} @ \mathrm{SiO}_{2}$-EDTA@Pt & 78.40 & 107.21 & 405.59 & 536.88 & 201.29 \\
$\mathrm{Fe}_{3} \mathrm{O}_{4} @ \mathrm{SiO}_{2}$-DTPA@Pt & 76.80 & 106.40 & 403.23 & 536.86 & 200.40 \\
$\mathrm{Fe}_{3} \mathrm{O}_{4} @ \mathrm{SiO}_{2}$-AP & - & 108.78 & 407.24 & 537.60 & - \\
$\mathrm{H}_{2} \mathrm{PtCl}_{6} \cdot 6 \mathrm{H}_{2} \mathrm{O}$ & 73.10 & - & - & - & 199.50 \\
${ }^{a}$ The banding energies are referred to C 1s (284.6 eV). &
\end{tabular}

observed using microscope, these nanoparticles were monodisperse. It means the aggregation is temporary in BET analysis. The BET data including surface area, average pore size and total pore volume derived from the isotherms were calculated. The BET specific surface area, the pore size and the total pore volume of $\mathrm{Fe}_{3} \mathrm{O}_{4} @ \mathrm{SiO}_{2}$-EDTA@Pt were $75.68 \mathrm{~m}^{2} \mathrm{~g}^{-1}, 17.50 \mathrm{~nm}$ and $0.685 \mathrm{~cm}^{3} \mathrm{~g}^{-1}$, respectively. They were corresponding to $36.65 \mathrm{~m}^{2} \mathrm{~g}^{-1}, 29.86 \mathrm{~nm}$ and $0.366 \mathrm{~cm}^{3} \mathrm{~g}^{-1}$ for $\mathrm{Fe}_{3} \mathrm{O}_{4} @ \mathrm{SiO}_{2}-$ DTPA@Pt.

To test the thermal stability and the grafting amount of carboxyl groups on the magnetic silica nanoparticles, TGA analysis was performed for $\mathrm{Fe}_{3} \mathrm{O}_{4} @ \mathrm{SiO}_{2}$-EDTA@Pt and $\mathrm{Fe}_{3}$ $\mathrm{O}_{4} @ \mathrm{SiO}_{2}$-DTPA@Pt nanoparticles (Fig. 6b.). As shown in the TGA curve of the prepared nanoparticles, the weight loss below $200{ }^{\circ} \mathrm{C}$ was attributed to the removal the water, and the organic parts were decomposed completely at about $700{ }^{\circ} \mathrm{C}$. The TGA curve of bare $\mathrm{Fe}_{3} \mathrm{O}_{4} @ \mathrm{SiO}_{2}$ nanoparticles showed that the weight loss over a temperature range from 50 to $800{ }^{\circ} \mathrm{C}$ was about $4 \%$, which was attributed to the escape of physically adsorbed water or/and structural water on the surface ${ }^{64}$ Moreover, the weight increases slightly in the temperature range of $700-800{ }^{\circ} \mathrm{C}$, which might be caused by the slight oxidation of $\mathrm{Fe}_{3} \mathrm{O}_{4} \cdot{ }^{65}$ For $\mathrm{Fe}_{3}$ $\mathrm{O}_{4} @ \mathrm{SiO}_{2}$-EDTA@Pt and $\mathrm{Fe}_{3} \mathrm{O}_{4} @ \mathrm{SiO}_{2}$-DTPA@Pt nanoparticles, the weight loss at temperatures below $200{ }^{\circ} \mathrm{C}$ was about $3 \%$, which was related to the release of moisture and structural water on the surface of the silica layer. However, apart from the water loss, organic components inside the particles began to degrade rapidly at a temperature higher than $200{ }^{\circ} \mathrm{C}$, and almost completely decomposed at $550{ }^{\circ} \mathrm{C}$ for $\mathrm{Fe}_{3} \mathrm{O}_{4} @ \mathrm{SiO}_{2}$ EDTA@Pt and $700{ }^{\circ} \mathrm{C}$ for $\mathrm{Fe}_{3} \mathrm{O}_{4} @ \mathrm{SiO}_{2}$-DTPA@Pt, respectively. Therefore, the weight loss from 200 to $800{ }^{\circ} \mathrm{C}$ in the TGA curves of $\mathrm{Fe}_{3} \mathrm{O}_{4} @ \mathrm{SiO}_{2}$-EDTA@Pt (about 28 wt\%) and $\mathrm{Fe}_{3} \mathrm{O}_{4} @ \mathrm{SiO}_{2}$ DTPA@Pt (about $30 \mathrm{wt} \%$ ) could be used to estimate the weight proportions of EDTA or DTPA-modified on $\mathrm{Fe}_{3} \mathrm{O}_{4} @ \mathrm{SiO}_{2}$. This phenomenon suggested that the weight proportion of multicarboxyl groups on $\mathrm{Fe}_{3} \mathrm{O}_{4} @ \mathrm{SiO}_{2}$-DTPA@Pt (30 wt\%) was higher than that on $\mathrm{Fe}_{3} \mathrm{O}_{4} @ \mathrm{SiO}_{2}$-EDTA@Pt (28 wt\%). It was consistent with one more carboxyl group in DTPA than EDTA.

The key for magnetic materials is the sufficient magnetic property. Therefore the magnetic properties of these nanoparticles were analyzed by VSM (Fig. 7.). The saturation magnetization was found to be 74.7, 48.4, 44.4, 25.4 and 23.0 emu $\mathrm{g}^{-1}$ for $\mathrm{Fe}_{3} \mathrm{O}_{4}, \mathrm{Fe}_{3} \mathrm{O}_{4} @ \mathrm{SiO}_{2}, \mathrm{Fe}_{3} \mathrm{O}_{4} @ \mathrm{SiO}_{2}-\mathrm{AP}, \mathrm{Fe}_{3} \mathrm{O}_{4} @ \mathrm{SiO}_{2}-$ EDTA@Pt and $\mathrm{Fe}_{3} \mathrm{O}_{4} @ \mathrm{SiO}_{2}$-DTPA@Pt, respectively. All of them showed superparamagnetic properties due to the presence of nanometer-sized magnetic $\mathrm{Fe}_{3} \mathrm{O}_{4}$ particles in the core. ${ }^{66}$
Although the saturation magnetization values of $\mathrm{Fe}_{3} \mathrm{O}_{4} @ \mathrm{SiO}_{2}$ EDTA@Pt and $\mathrm{Fe}_{3} \mathrm{O}_{4} @ \mathrm{SiO}_{2}$-DTPA@Pt were lower than that of $\mathrm{Fe}_{3} \mathrm{O}_{4}, \mathrm{Fe}_{3} \mathrm{O}_{4} @ \mathrm{SiO}_{2}$ and $\mathrm{Fe}_{3} \mathrm{O}_{4} @ \mathrm{SiO}_{2}-\mathrm{AP}$, they could be readily separated from their dispersion in $1 \mathrm{~min}$ with an external magnetic field owing to their high magnetite content and thus good magnetic response (Fig. 7, inset). These results indicated that the magnetization of $\mathrm{Fe}_{3} \mathrm{O}_{4}$ decreases considerably after coated with $\mathrm{SiO}_{2}$ due to the weight contribution from the nonmagnetic $\mathrm{SiO}_{2}$. Nevertheless, both of the catalysts exhibited enough magnetic response to meet the need of magnetic separation.

\subsection{Catalyst performances for hydrosilylation}

3.3.1 Activity and reusability in catalyzing hydrosilylation of 1-hexene. Hydrosilylation of alkene with silane is a typical reaction catalyzed by platinum, which exist two reaction pathways $\alpha$-addition and $\beta$-addition. ${ }^{67,68}$ Hydrosilylation of a series of alkenes with methyldichlorosilane were catalyzed by the two novel $\mathrm{Pt}$ catalysts, $\mathrm{Fe}_{3} \mathrm{O}_{4} @ \mathrm{SiO}_{2}$-EDTA@Pt and $\mathrm{Fe}_{3} \mathrm{O}_{4} @ \mathrm{SiO}_{2}$ DTPA@Pt, to evaluate their activity and regioselectivity.

Hydrosilylation conditions are important for yield and regioselectivity. To exhibit well the activities of two catalysts, we optimized hydrosilylation conditions of 1-hexene and methyldichlorosilane, including reaction temperatures $(30,40,50,60$, 70 , and $\left.80{ }^{\circ} \mathrm{C}\right)$, times $(0.5,1,2,3,4$, and $5 \mathrm{~h})$, the molar ratio of methyldichlorosilane and 1-hexene $(0.5: 1.0,1.0: 1.0,1.2: 1.0$, $1.5: 1.0,1.8: 1.0$, and $2.0: 1.0)$ and the additive sequence of 1 hexene and methyldichlorosilane (1-hexene added to methyldichlorosilane after methyldichlorosilane mixing with the catalyst for $30 \mathrm{~min}$, simultaneous addition of 1-hexene and methyldichlorosilane, methyldichlorosilane added to 1-hexene after mixing with the catalyst for $30 \mathrm{~min}$ ). The detail results were summarized in support information (Fig. 1S $\dagger$ ). Results indicated both $\mathrm{Fe}_{3} \mathrm{O}_{4} @ \mathrm{SiO}_{2}$-EDTA@Pt and $\mathrm{Fe}_{3} \mathrm{O}_{4} @ \mathrm{SiO}_{2}$-DTPA@Pt (containing $2.01 \times 10^{-3} \mathrm{mmol} \mathrm{Pt}$ in each catalyst) could efficiently catalyze the hydrosilylation. The yields were up to $99.4 \%$ and $98.77 \%$ when $19.2 \mathrm{mmol}$ methyldichlorosilane was added to $11.8 \mathrm{mmol}$ 1-hexene after mixing with the catalyst for $30 \mathrm{~min}$ and maintained the reaction $3 \mathrm{~h}$ at $50-60{ }^{\circ} \mathrm{C}$. As a comparison, the yield only was $35.46 \%$ when $\mathrm{Fe}_{3} \mathrm{O}_{4} @ \mathrm{SiO}_{2} @ \mathrm{Pt}$ was used as catalyst.

In research of platinum catalyst, the turnover number (TON) of Pt often is used as criteria. Thus, we calculated the TON approached 3628 and 3550 when $\mathrm{Fe}_{3} \mathrm{O}_{4} @ \mathrm{SiO}_{2}$-EDTA@Pt and $\mathrm{Fe}_{3} \mathrm{O}_{4} @ \mathrm{SiO}_{2}$-DTPA@Pt with $2.60 \mu \mathrm{mol}$ Pt catalyzed $11.2 \mathrm{mmol}$ of 1-hexene in $4 \mathrm{~h}$. To further increase the TON for hydrosilylation, amount of Pt catalyst was gradually decreased to 2.10, $1.82,1.47,0.87$, even $0.34 \mu \mathrm{mol}$. Results indicated the hydrosilylation between 1-hexene and methyldichlorosilane with low amount of Pt could be catalyzed and the TON quickly increased to $4721,5435,6744,10905$ and 16006 for $\mathrm{Fe}_{3} \mathrm{O}_{4} @ \mathrm{SiO}_{2}$ EDTA@Pt, 4750, 5464, 6794 and 10789 for $\mathrm{Fe}_{3} \mathrm{O}_{4} @ \mathrm{SiO}_{2}$ DTPA@Pt. Furthermore, we catalyzed the hydrosilylation of methyldichlorosilane $(180 \mathrm{mmol})$ and 1-hexene $(110 \mathrm{mmol})$ using only $0.3 \mathrm{mg} \mathrm{Fe}_{3} \mathrm{O}_{4} @ \mathrm{SiO}_{2}$-EDTA@Pt $(0.0052 \mu \mathrm{mol} \mathrm{Pt})$ or $0.3 \mathrm{mg} \mathrm{Fe}_{3} \mathrm{O}_{4} @ \mathrm{SiO}_{2}$-DTPA@Pt $(0.057 \mu \mathrm{mol} \mathrm{Pt})$ in $12 \mathrm{~h}$. 

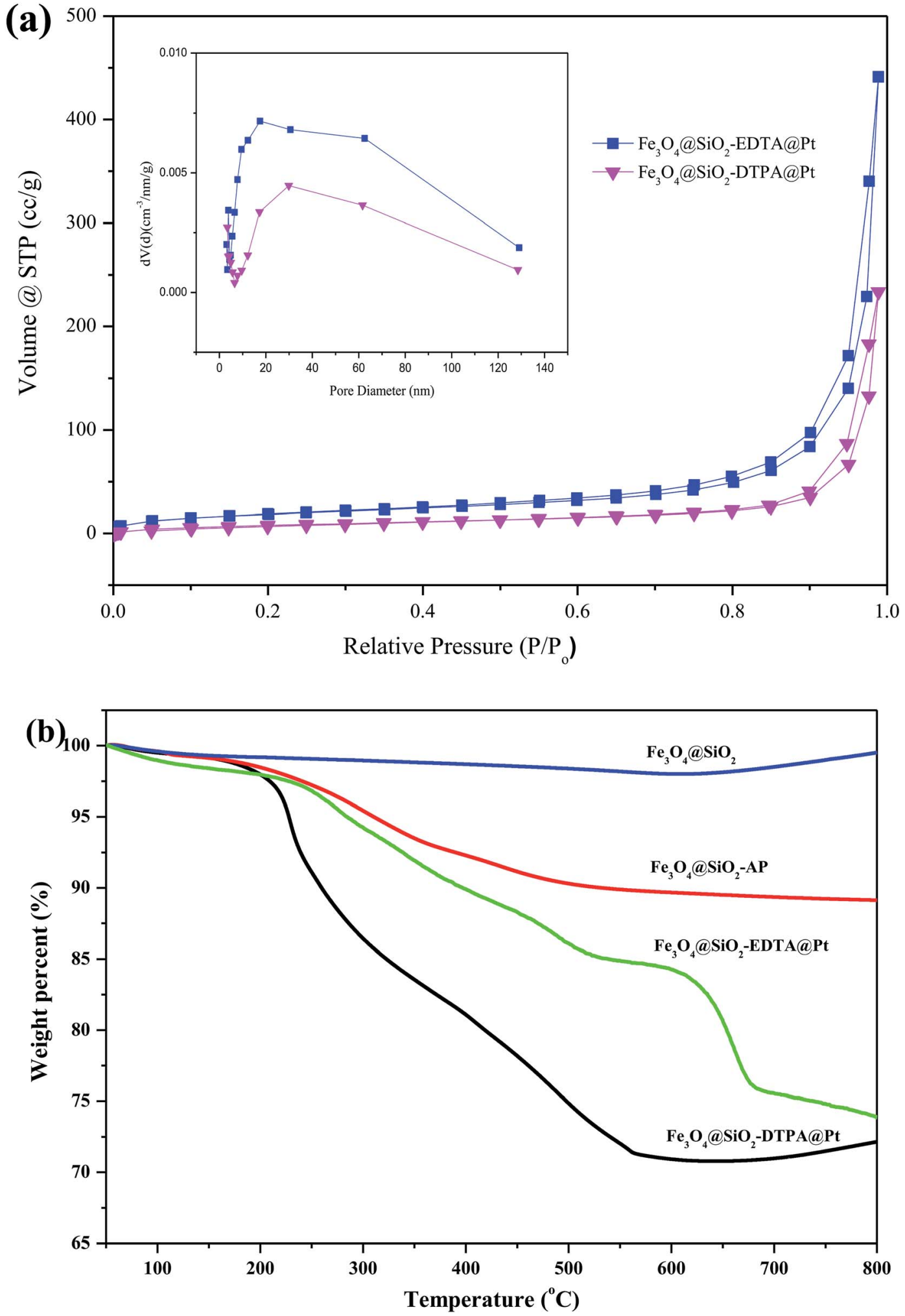

Fig. 6 (a) Nitrogen adsorption-desorption isotherms and (inset) the corresponding pore-size distribution curves of $\mathrm{Fe}_{3} \mathrm{O}_{4} \mathrm{QSSiO}_{2}, \mathrm{Fe}_{3} \mathrm{O}_{4} \mathrm{aSiO}_{2}-$ AP, $\mathrm{Fe}_{3} \mathrm{O}_{4} \mathrm{aSiO}_{2}$-EDTA@Pt and $\mathrm{Fe}_{3} \mathrm{O}_{4} \mathrm{aSiO}_{2}$-DTPA@Pt catalysts, (b) TGA curves of $\mathrm{Fe}_{3} \mathrm{O}_{4} \mathrm{aSiO}_{2}, \mathrm{Fe}_{3} \mathrm{O}_{4} @ \mathrm{aSiO}_{2}-\mathrm{AP}, \mathrm{SiO}_{2} @ \mathrm{Fe}_{3} \mathrm{O}_{4}$-EDTA@Pt and $\mathrm{SiO}_{2} \mathrm{aFe}_{3} \mathrm{O}_{4}$-DTPA@Pt.

Remarkably, the region-selectivity was still around $99 \%$ and TON increased to 662733 for $\mathrm{Fe}_{3} \mathrm{O}_{4} @ \mathrm{SiO}_{2}$-EDTA@Pt, 579947 for $\mathrm{Fe}_{3} \mathrm{O}_{4} @ \mathrm{SiO}_{2}$-DTPA@Pt, respectively.
Usually, the stability of a catalyst is an important characteristic before it can be used in an industrial application. Therefore, the reusability of $\mathrm{Fe}_{3} \mathrm{O}_{4} @ \mathrm{SiO}_{2}$-EDTA@Pt and 


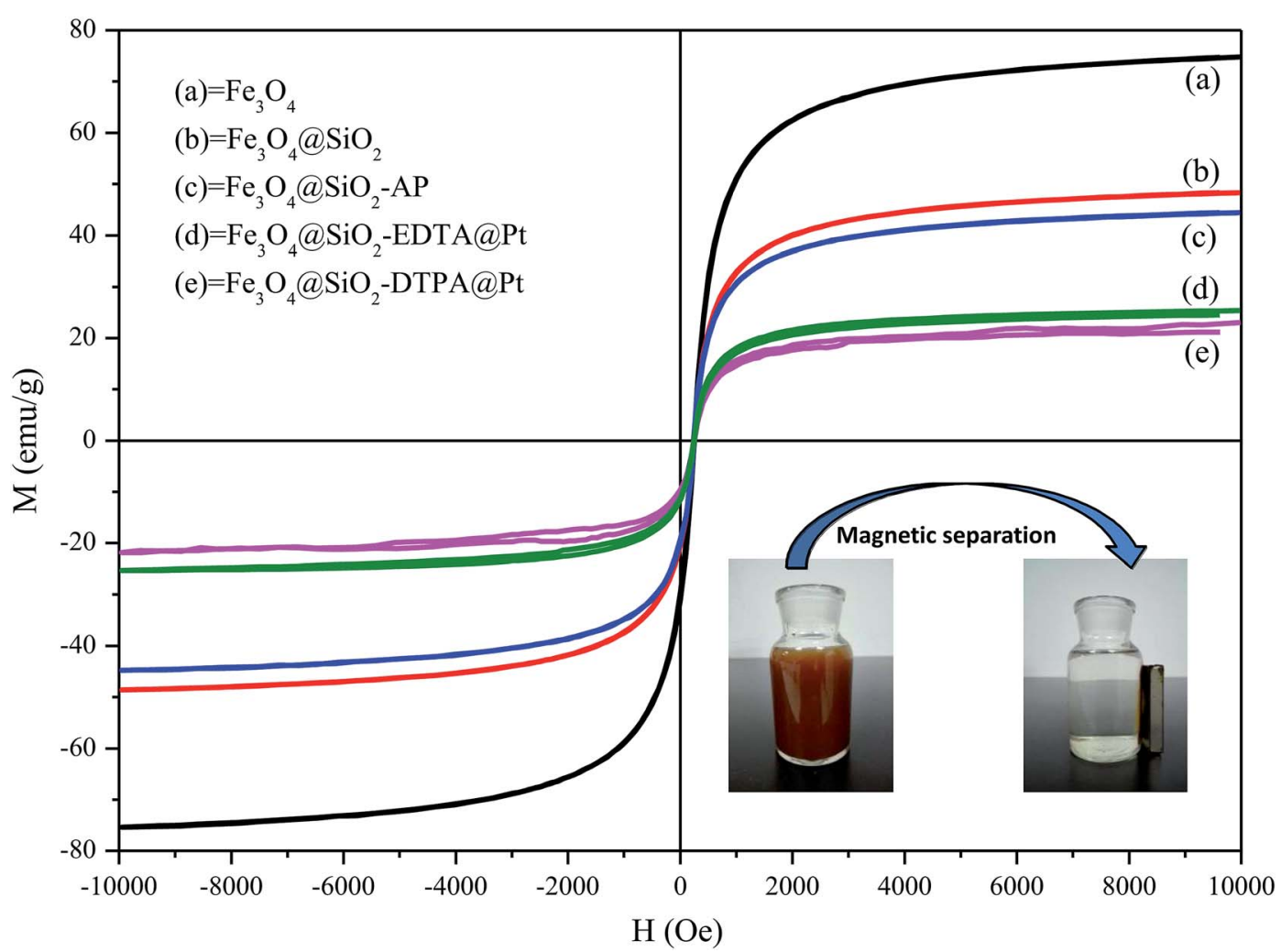

Fig. 7 VSM magnetization curves of $\mathrm{Fe}_{3} \mathrm{O}_{4}, \mathrm{Fe}_{3} \mathrm{O}_{4} \mathrm{aSiO}_{2}, \mathrm{Fe}_{3} \mathrm{O}_{4} \mathrm{aSiO}_{2}-\mathrm{AP}, \mathrm{Fe}_{3} \mathrm{O}_{4} \mathrm{aSiO}_{2}$-EDTA@Pt and Fe $\mathrm{O}_{4} @ \mathrm{CSiO}_{2}$-DTPA@Pt. Inset: magnetic separation of $\mathrm{Fe}_{3} \mathrm{O}_{4}\left(\mathrm{aSiO}_{2}-\mathrm{EDTA} @ \mathrm{Pt}\right.$ and $\mathrm{Fe}_{3} \mathrm{O}_{4} \mathrm{aSiO}_{2}-\mathrm{DTPA} @ \mathrm{Pt}$ from the aqueous suspensions.

$\mathrm{Fe}_{3} \mathrm{O}_{4} @ \mathrm{SiO}_{2}$-DTPA@Pt catalysts were evaluated through repetitively catalyzing the hydrosilylation of 1-hexene with methyldichlorosilane. A series of 12 consecutive hydrosilylation reactions were carried out under optimal reaction conditions. After each catalytic reaction, the two platinum catalysts were held in the original system using a magnet and catalyzed next hydrosilylation without any other process. The results were showed in Fig. 8. Data showed a satisfactory yield of 1-heptylmethyldichlorosilane (about $90 \%$ after 12 catalytic runs for both of Pt catalysts) which was apparent better than the Pt catalysts immobilized on non-magnetic $\mathrm{SiO}_{2}$ supports (only $80 \%$ after 12 or 13 runs). ${ }^{36,37}$ After 12 runs, the magnetism both of Pt catalysts were similar and the platinum amount was $155.78 \mathrm{mmol} \mathrm{g}^{-1}$ for $\mathrm{Fe}_{3} \mathrm{O}_{4} @ \mathrm{SiO}_{2}$-EDTA@Pt and $177.62 \mathrm{mmol} \mathrm{g}^{-1}$ for $\mathrm{Fe}_{3} \mathrm{O}_{4} @ \mathrm{SiO}_{2}-$ DTPA@Pt. There were only $10.4 \%$ Pt loss in $\mathrm{Fe}_{3} \mathrm{O}_{4} @ \mathrm{SiO}_{2}$ EDTA@Pt and 7.9\% Pt loss in $\mathrm{Fe}_{3} \mathrm{O}_{4} @ \mathrm{SiO}_{2}$-DTPA@Pt. The average loss of Pt was $0.87 \%$ for $\mathrm{Fe}_{3} \mathrm{O}_{4} @ \mathrm{SiO}_{2}$-EDTA@Pt and $0.66 \%$ for $\mathrm{Fe}_{3} \mathrm{O}_{4} @ \mathrm{SiO}_{2}$-DTPA@Pt in each reaction which was apparent better than homogeneous Pt catalyst (about $10 \mathrm{ppm}$ ) and Pt catalysts immobilized on non-magnetic support. The data were listed in Table S1. $\dagger$ In order to identify the active species of Pt catalysts, the state of Pt catalysts in high-resolution XPS after recycle experiments was tested. The data were listed in Fig. S3 and Table S2. $\dagger$ The total amount of $\mathrm{Pt}^{2+}$ and $\mathrm{Pt}^{0}$ was $71.1 \%$ (before recycle) and 76.1\% (after recycle) for $\mathrm{Fe}_{3} \mathrm{O}_{4} @ \mathrm{SiO}_{2}-$ EDTA@Pt. The total amount of $\mathrm{Pt}^{2+}$ and $\mathrm{Pt}^{0}$ was $73.6 \%$ (before recycle) and $79.6 \%$ (after recycle) for $\mathrm{Fe}_{3} \mathrm{O}_{4} @ \mathrm{SiO}_{2}$-DTPA@Pt.
According to the data, there wasn't the apparent state change of the recycled Pt catalyst in both $\mathrm{Fe}_{3} \mathrm{O}_{4} @ \mathrm{SiO}_{2}$-EDTA@Pt and $\mathrm{Fe}_{3} \mathrm{O}_{4} @ \mathrm{SiO}_{2}$-DTPA@Pt. This also indicated both of catalysts, especially $\mathrm{Fe}_{3} \mathrm{O}_{4} @ \mathrm{SiO}_{2}$-DTPA@Pt, were very stable, which maybe result from strong coordination interaction between carboxyl group and the metallic Pt. The residual four carboxyl groups of DTPA in $\mathrm{Fe}_{3} \mathrm{O}_{4} @ \mathrm{SiO}_{2}$-DTPA maybe produce a stronger interaction with $\mathrm{Pt}$ than the residual three carboxyl groups of EDTA in $\mathrm{Fe}_{3} \mathrm{O}_{4} @ \mathrm{SiO}_{2}$-EDTA (Table 2).

\subsubsection{Catalyzing hydrosilylation of internal and terminal} hexene. The unprecedented activity and selectivity of the two Pt nanoparticle catalysts prompted us to further exploit its potential applications in the isomerization-hydrosilylation tandem process. Five hexene, including 1-hexene, trans-2-hexene, cis-2-hexene, trans-3-hexene and cis-3-hexene were used as alkene. The hydrosilylation between methyldichlorosilane and hexene were catalyzed by $\mathrm{Fe}_{3} \mathrm{O}_{4} @ \mathrm{SiO}_{2}$-EDTA@Pt or $\mathrm{Fe}_{3} \mathrm{O}_{4} @$ $\mathrm{SiO}_{2}$-DTPA@Pt under the aforementioned optimal conditions. Products were monitored by GC and NMR (see Fig. S2 in ESI †े). Data were summarized in Table 3. It was interesting that the main product was 1-hexylmethyldichlorosilane in hydrosilylation of all of hexene, which was typical isomerizationhydrosilylation and the $\beta$-adduct as a major product. The similar phenomena were observed in previous studies. ${ }^{69,70} \mathrm{We}$ bought the standard substance of 1-hexylmethyldichlorosilane which was compared with the synthesized 1-hexylmethyldichlorosilane, in GC chromatograms, all 1- 


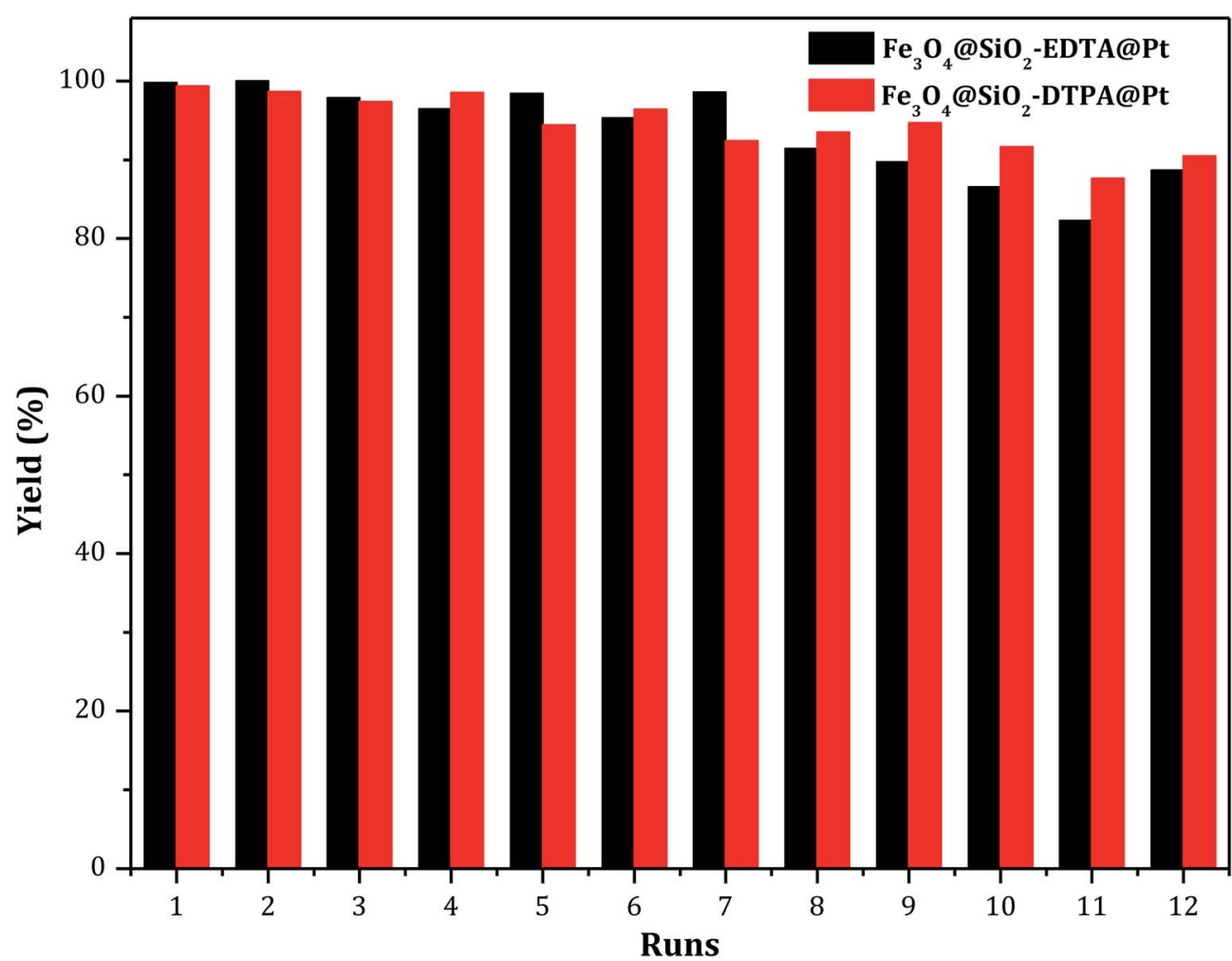

Fig. 8 Catalyst recycle experiments for the hydrosilylation of 1-hexene with methyldichlorosilane.

hexylmethyldichlorosilane peek shown at around $8.45 \mathrm{~min}$. For NMR: ${ }^{1} \mathrm{H}$ NMR (600 MHz, $\left.\mathrm{CDCl}_{3}\right) \delta: 1.50\left(\mathrm{~m}, 2 \mathrm{H}, \mathrm{CH}_{3}-\left(\mathrm{CH}_{2}\right)_{3}-\right.$ $\left.\mathrm{CH}_{2}-\mathrm{CH}_{2}-\mathrm{SiCl}_{2}-\mathrm{CH}_{3}\right), 1.38\left(\mathrm{~m}, 2 \mathrm{H}, \mathrm{CH}_{3}-\left(\mathrm{CH}_{2}\right)_{2}-\mathrm{CH}_{2}-\left(\mathrm{CH}_{2}\right)_{2}-\right.$ $\left.\mathrm{SiCl}_{2}-\mathrm{CH}_{3}\right), 1.20\left(\mathrm{~s}, 4 \mathrm{H}, \mathrm{CH}_{3}-\left(\mathrm{CH}_{2}\right)_{2}-\left(\mathrm{CH}_{2}\right)_{3}-\mathrm{SiCl}_{2}-\mathrm{CH}_{3}\right), 1.12$ (m, $\left.2 \mathrm{H}, \mathrm{CH}_{3}-\left(\mathrm{CH}_{2}\right)_{4}-\mathrm{CH}_{2}-\mathrm{SiCl}_{2}-\mathrm{CH}_{3}\right), 0.88\left(\mathrm{t}, 3 \mathrm{H}, \mathrm{CH}_{3}-\left(\mathrm{CH}_{2}\right)_{5}-\right.$ $\left.\mathrm{SiCl}_{2}-\mathrm{CH}_{3}\right), 0.77\left(\mathrm{~s}, 3 \mathrm{H}, \mathrm{CH}_{3}-\left(\mathrm{CH}_{2}\right)_{5}-\mathrm{SiCl}_{2}-\mathrm{CH}_{3}\right)$.
The yield of 1-hexylmethyldichlorosilane changed in hydrosilylation of different hexane and methyldichlorosilane. When $\mathrm{Fe}_{3} \mathrm{O}_{4} @ \mathrm{SiO}_{2}$-EDTA@Pt was used as catalyst, the highest yield (97\%) was from 1-hexene. The yield of 1-hexylmethyldichlorosilane decreased to $95 \%$ for cis-2-hexene and $83 \%$ for cis3-hexene. When cis-2-hexene and cis-3-hexene were changed to

Table $2 \mathrm{Fe}_{3} \mathrm{O}_{4} @ \mathrm{SSiO}_{2}-\mathrm{EDTA} @ \mathrm{Pt}$ and $\mathrm{Fe}_{3} \mathrm{O}_{4} \mathrm{aSiO}_{2}$-DTPA@Pt-catalyzed tandem isomerization-hydrosilylation of trans- and cis-internal alkenes with methyldichlorosilane ${ }^{a}$

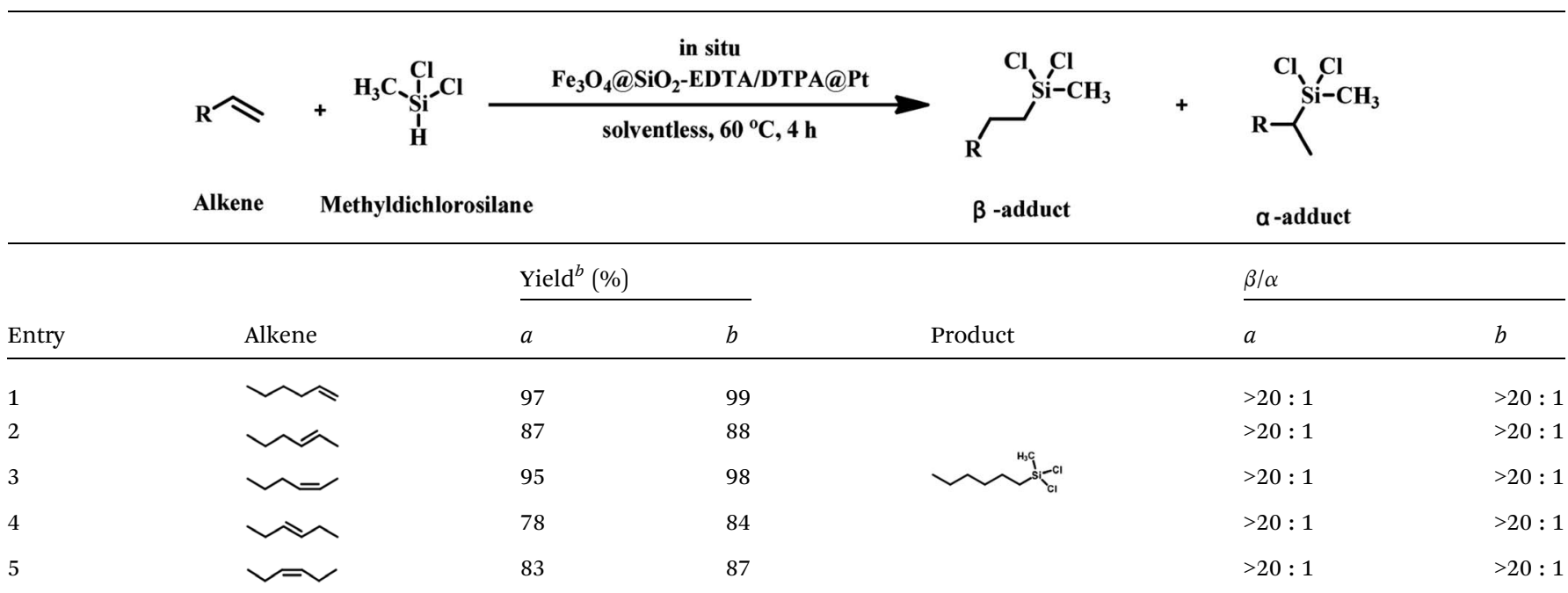

${ }^{a}$ Conditions: alkenes, $10 \mathrm{mmol}$; methyldichlorosilane, $15 \mathrm{mmol} ; 8 \mathrm{~h}$; a, $\mathrm{Fe}_{3} \mathrm{O}_{4} @ \mathrm{SiO}_{2}$-EDTA@Pt as catalyst; b $\mathrm{Fe}_{3} \mathrm{O}_{4} @ \mathrm{ESO}_{2}$-DTPA@Pt as catalyst. ${ }^{b}$ yield were determined by GC using $n$-decane as an internal standard. 
Table 3 Hydrosilylation of alkenes with methyldichlorosilane catalyzed by $\mathrm{Fe}_{3} \mathrm{O}_{4} \mathrm{aSiO}_{2}-\mathrm{EDTA}_{\mathrm{APt}}$ and $\mathrm{Fe}_{3} \mathrm{O}_{4} \mathrm{aSiO}_{2}-\mathrm{DTPA}_{\mathrm{CPt}}{ }^{a}$

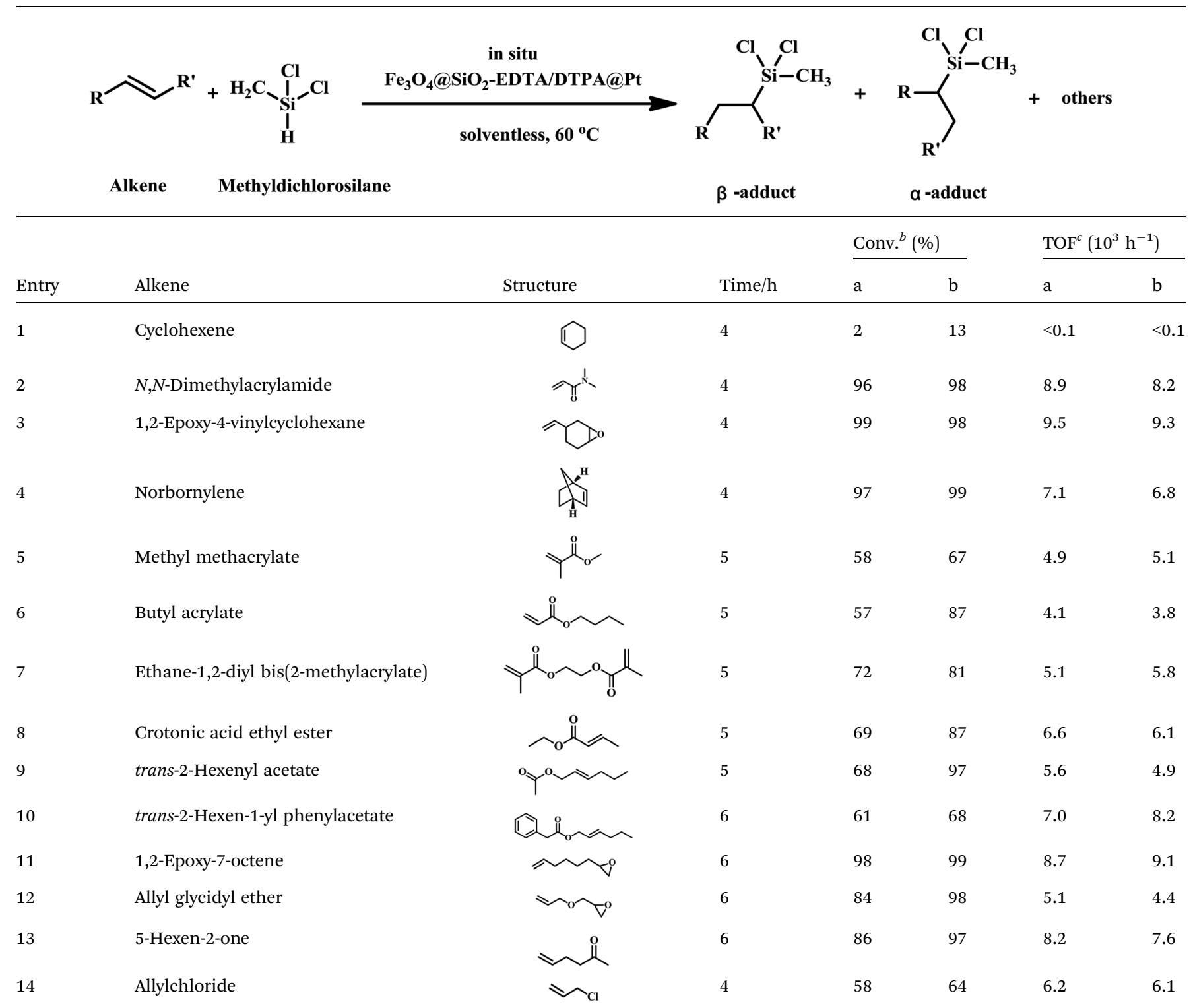

${ }^{a}$ Conditions: $15 \mathrm{mmol}$ methyldichlorosilane, $10 \mathrm{mmol}$ alkene; temperature: $60{ }^{\circ} \mathrm{C}$; a, $\mathrm{Fe}_{3} \mathrm{O}_{4} @ \mathrm{SiO}_{2}$-EDTA@Pt as catalyst $\left(1.74 \times 10^{-3} \mathrm{mmol} \mathrm{Pt}\right) ; \mathrm{b}$, $\mathrm{Fe}_{3} \mathrm{O}_{4} @ \mathrm{SiO}_{2}$-DTPA@Pt as catalyst $\left(1.93 \times 10^{-3} \mathrm{mmol} \mathrm{Pt}\right) .{ }^{b}$ The conversion was based on the amount of alkene consumed. ${ }^{c}$ Initial TOFs were calculated by GC after $30 \mathrm{~min}$ of reaction time.

trans-2-hexene and trans-3-hexene, the yield further decreased corresponding to $87 \%$ and $78 \%$. The similar phenomenon was observed when $\mathrm{Fe}_{3} \mathrm{O}_{4} @ \mathrm{SiO}_{2}$-DTPA@Pt was used as catalyst. It indicated the hydrosilylation was harder for internal hexane than 1-hexene and trans-hexene than cis-hexane. The results also verified both of Pt catalysts could be used for the remote functionalization of alkenes, which has been shown to be a remarkable step in organic synthesis. ${ }^{71,72}$

3.3.3 Catalyzing hydrosilylation of other alkenes. The catalytic activities of the two Pt nanoparticles were further evaluated through employing another 14 alkenes with different substituent, including nine terminal alkenes $(N, N$-dimethylacrylamide, 1,2-epoxy-4-vinylcyclohexane, methyl methacrylate, butyl acrylate, ethane-1,2-diyl bis(2-methylacrylate), 1,2-epoxy-7- octene, allyl glycidyl ether, 5-hexen-2-one and allylchloride), three trans- internal alkenes (crotonic acid ethyl ester, trans-2hexenyl acetate, and trans-2-hexen-1-yl phenylacetate) and two ring type alkenes (cyclohexene and norbornylene). These compounds are important industry raw materials. For example, allyl glycidyl ether is an important substrate because the alkoxysilanes derived from this alkene have broad applications in coatings and as coupling agents for epoxy composites used as electronic chip encapsulation. ${ }^{73}$ Catalytic results were summarized in Table 3. The multi-products were observed in GC chromatograms, different substrates peak at different times due to the diversity of their boiling point, for example, cyclohexene peek at around $6.86 \mathrm{~min}, 1,2$-epoxy-4-vinylcyclohexane peek at around $9.55 \mathrm{~min}$, and allyl glycidyl ether peek at around 
$8.18 \mathrm{~min}$. Because of multi-products were observed, $n$-decane used as internal standard to get alkene conversion, which used to evaluate the versatility of the prepared catalysts. Various linear alkenes containing either electron-donating or electronwithdrawing groups such as amine (entry 2), ester (entries 510), epoxide (entries 3, 11, and 12), ketone (entry 13), alkyl chloride (entry 14) and ring type norbornylene (entry 4) except cyclohexene (entry 1) were well catalyzed by $\mathrm{Fe}_{3} \mathrm{O}_{4} @ \mathrm{SiO}_{2}$ EDTA@Pt and $\mathrm{Fe}_{3} \mathrm{O}_{4} @ \mathrm{SiO}_{2}$-DTPA@Pt. In catalyzing $N, N$-dimethylacrylamide, 1,2-epoxy-4-vinylcyclohexane, norbornylene, and 1,2-epoxy-7-octene, both $\mathrm{Fe}_{3} \mathrm{O}_{4} @ \mathrm{SiO}_{2}$-EDTA@Pt and $\mathrm{Fe}_{3}$ $\mathrm{O}_{4} @ \mathrm{SiO}_{2}$-DTPA@Pt showed similar high activity (>96\%). The catalytic activity of $\mathrm{Fe}_{3} \mathrm{O}_{4} @ \mathrm{SiO}_{2}$-DTPA@Pt was significantly higher than $\mathrm{Fe}_{3} \mathrm{O}_{4} @ \mathrm{SiO}_{2}$-EDTA@Pt in hydrosilylation of crotonic acid ethyl ester, trans-2-hexen-1-yl phenylacetate, trans-2hexenyl acetate, methyl methacrylate, butyl acrylate, ethane-1,2diyl bis(2-methylacrylate), allyl glycidyl ether, 5-hexen-2-one and allylchloride. Even $\mathrm{Fe}_{3} \mathrm{O}_{4} @ \mathrm{SiO}_{2}$-DTPA@Pt could catalyze the hydrosilylation of cyclohexene $(13 \%)$, whereas a very low yield (2\%) in $\mathrm{Fe}_{3} \mathrm{O}_{4} @ \mathrm{SiO}_{2}$-EDTA@Pt as catalyst. These results indicated $\mathrm{Fe}_{3} \mathrm{O}_{4} @ \mathrm{SiO}_{2}$-EDTA@Pt was more efficient.

\section{Conclusions}

Two novel magnetic $\mathrm{Fe}_{3} \mathrm{O}_{4} @ \mathrm{SiO}_{2}$-EDTA@Pt and $\mathrm{Fe}_{3} \mathrm{O}_{4} @ \mathrm{SiO}_{2}$ DTPA@Pt catalysts were successfully prepared. The saturation magnetization was 25.4 and 23.0 emu $\mathrm{g}^{-1}$ for $\mathrm{Fe}_{3} \mathrm{O}_{4} @ \mathrm{SiO}_{2}$ EDTA@Pt and $\mathrm{Fe}_{3} \mathrm{O}_{4} @ \mathrm{SiO}_{2}$-DTPA@Pt, respectively. The Pt amount of the $30-50 \mathrm{~nm}$ nanoparticles was corresponding to 173.80 and $192.77 \mu \mathrm{mol} \mathrm{g}^{-1}$, which the predominant valence was $\mathrm{Pt}^{2+}$ and $\mathrm{Pt}^{0}$. In catalyzing hydrosilylation of 1-hexene and methyldichlorosilane, the yield of 1-heptylmethyldichlorosilane was about $99 \%$ for both of catalysts and the TON were up to 662733 for $\mathrm{Fe}_{3} \mathrm{O}_{4} @ \mathrm{SiO}_{2}$-EDTA@Pt and 579947 for $\mathrm{Fe}_{3} \mathrm{O}_{4} @$ @$\mathrm{SiO}_{2}$-DTPA@Pt, respectively. The two catalysts, especially $\mathrm{Fe}_{3}$ $\mathrm{O}_{4} @ \mathrm{SiO}_{2}$-DTPA@Pt, showed good activity in hydrosilylation of 5 isomerous hexanes and 14 other alkene with different substituent. $\mathrm{Fe}_{3} \mathrm{O}_{4} @ \mathrm{SiO}_{2}$-DTPA@Pt even could catalyze the hydrosilylation of cyclohexene. After 12 catalytic runs for both of Pt catalysts, yield of 1-heptylmethyldichlorosilane was still up to $90 \%$ and the magnetism was similar. The average loss of Pt in each reaction was $0.87 \%$ for $\mathrm{Fe}_{3} \mathrm{O}_{4} @ \mathrm{SiO}_{2}$-EDTA@Pt and $0.66 \%$ for $\mathrm{Fe}_{3} \mathrm{O}_{4} @ \mathrm{SiO}_{2}$-DTPA@Pt. The unprecedented activity and selectivity of the two Pt nanoparticle catalysts are prospective and potential in catalyzing more reactions and replacing the current homogeneous Pt catalyst industry.

\section{Conflicts of interest}

There are no conflicts to declare.

\section{Acknowledgements}

The authors would like to appreciate the financial supports from the National Natural Science foundation of China (No. 21605112).

\section{References}

1 R. M. Cornell and U. Schwertmann, The Iron Oxides: Structure, Properties, Reactions, Occurrence and Uses, VCH Publications, Weinheim, New York, 1996.

2 S. Xuan, Y. X. Wang, J. C. Yu and K. C. Leung, Langmuir, 2009, 25, 11835-11843.

3 B. Gaihre, M. S. Khil, D. R. Lee and H. Y. Kim, Int. J. Pharm., 2009, 365, 180-189.

4 N. Kohler, C. Sun, A. Fichtenholtz, J. Gunn, C. Fang and M. Zhang, Small, 2006, 2, 785-792.

5 H. Lee, M. K. Yu, S. Park, S. Moon, J. J. Min, Y. Y. Jeong, H. W. Kang and S. Jon, J. Am. Chem. Soc., 2007, 129, 12739-12745.

6 H. Liu, Z. Jia, S. Ji, Y. Zheng, M. Li and H. Yang, Catal. Today, 2011, 175, 293-298.

7 A. M. Donia, A. A. Atia and K. Z. Elwakeel, J. Hazard. Mater., 2008, 151, 372-379.

8 N. Nuryono, N. M. Rosiati, B. Rusdiarso, S. C. W. Sakti and S. Tanaka, SpringerPlus, 2014, 3, 515-526.

9 S. Hokkanen, E. Repo, S. Lou and M. Sillanpaa, Chem. Eng. J., 2015, 260, 886-894.

10 X. Sun, Q. Li, L. Yang and H. Liu, Particuology, 2016, 26, 7986.

11 A. Khazaei, M. Khazaei and M. Nasrollahzadeh, Tetrahedron, 2017, 73, 5624-5633.

12 Y. Fang, Y. Chen, X. Li, X. Zhou, J. Li, W. Tang, J. Huang, J. Jin and J. Ma, J. Mol. Catal. A: Chem., 2014, 392, 16-21.

13 B. Panella, A. Vargas and A. Baiker, J. Catal., 2009, 261, 8893.

14 R. L. Oliveira, P. K. Kiyohara and L. M. Rossi, Green Chem., 2010, 12, 144-149.

15 M. Amir, U. Kurtan and A. Baykal, Chin. J. Catal., 2015, 36, 1280-1286.

16 J. Sun, Z. Dong, X. Sun, P. Li, F. Zhang, W. Hu, H. Yang, H. Wang and R. Li, J. Mol. Catal. A: Chem., 2013, 367, 46-51.

17 J. J. Martíneza, E. X. Aguileraa, J. Cubillosa, H. Rojasa, A. Gómez-Cortésb and G. Díaz, Mol. Catal., 2019, 465, 54-60.

18 S. A. Theofanidis, V. V. Galvita, H. Poelman, R. Batchu, L. C. Buelens, C. Detavernier and G. B. Marin, J. Mol. Catal. B: Enzym., 2018, 239, 502-512.

19 Z. Mohamed, V. D. Dasireddy, S. Singh and H. B. Friedrich, Int. J. Hydrogen Energy, 2018, 43, 22291-22302.

20 B. Cheng, W. Liu and Z. Lu, J. Am. Chem. Soc., 2018, 140, 5014-5017.

21 B. Panella, A. Vargas and A. Baiker, J. Catal., 2009, 261, 8893.

22 M. Walczak, K. Stefanowska, A. Franczyk, J. Walkowiak, A. Wawrzynczak and B. Marciniec, J. Catal., 2018, 367, 1-6.

23 T. Yang, Y. Huo, Y. Liu, Z. Rui and H. Ji, Appl. Catal., B, 2017, 200, 543-551.

24 H. A. Khan, P. Natarajan and K. Jung, Appl. Catal., B, 2018, 231, 151-160.

25 H. Zai, Y. Zhao, S. Chen, L. Ge and C. Chen, Nano Res., 2018, 61, 2544-2552. 
26 Q. Li, S. Ji, M. Li and X. Duan, Sci. China Mater., 2018, 11, 1339-1344.

27 M. Mahmoudi, S. Sant, B. Wang, S. Laurent and T. Sen, Adv. Drug Delivery Rev., 2011, 63, 24-46.

28 R. T. Yang, Adsorbents: Fundamentals and Applications, John Wiley \& Sons, USA, 2003.

29 A. Lu, E. L. Salabas and F. Schüth, Angew. Chem., Int. Ed., 2007, 46, 1222-1244.

30 G. Zeng, Y. Pang, Z. Zeng, L. Tang, Y. Zhang, Y. Liu, J. Zhang, X. Lei, Z. Li, Y. Xiong and G. Xie, Langmuir, 2012, 28, 468473.

31 J. Ramo, M. Sillanpaa, V. Vickackaite, M. Orama and L. Niinisto, J. Pulp Pap. Sci., 2000, 26, 125-131.

32 J. Ramo and M. Sillanpaa, J. Cleaner Prod., 2001, 9, 191-195.

33 M. E. T. Sillanpaa and J. H. P. Ramo, Environ. Sci. Technol., 2001, 35, 1379-1384.

34 M. Sillanpaa, M. Orama, J. Ramo and A. Oikari, Sci. Total Environ., 2001, 267, 23-31.

35 K. Pirkanniemi, S. Metsarinne and M. Sillanpaa, J. Hazard. Mater., 2007, 147, 556-561.

36 F. Li and Y. Li, J. Mol. Catal. A: Chem., 2016, 420, 254-263.

37 D. Shao and Y. Li, RSC Adv., 2018, 8, 20379-20393.

38 Z. Lu, G. Wang, J. Zhuang and W. Yang, Colloids Surf., A, 2006, 278, 140-143.

39 Y. S. Kang, S. Risbud, J. F. Rabolt and P. Stroeve, Chem. Mater., 1996, 8, 2209-2211.

40 S. Zhang, H. Niu, Y. Zhang, J. Liu, Y. Shi, X. Zhang and Y. Cai, J. Chromatogr. A, 2012, 1238, 38-45.

41 Y. Deng, D. Qi, C. Deng, X. Zhang and D. Zhao, J. Am. Chem. Soc., 2008, 130, 28-29.

42 M. J. Jacinti, O. H. Santos, R. Landers, P. K. Kiyohara and L. M. Rossi, Appl. Catal., B, 2009, 90, 688-692.

43 Z. Ma, Y. Guan and H. Liu, J. Magn. Magn. Mater., 2006, 301, 469-477.

44 Q. Yuan, N. Li, Y. Chi, W. Geng, W. Yan, Y. Zhao, X. Li and B. Dong, J. Hazard. Mater., 2013, 254-255, 157-165.

45 X. Sun, Q. Li, L. Yang and H. Liu, Particuology, 2016, 26, 7986.

46 M. J. Jacinto, P. K. Kiyohara, S. H. Masunaga, R. F. Jardim and L. M. Rossi, Appl. Catal., A, 2008, 338, 52-57.

47 M. Tülü and K. E. Geckeler, Polym. Int., 1999, 48, 909-914. 48 Y. Liu, M. Chen and Y. Hao, Chem. Eng. J., 2013, 218, 46-54. 49 Y. Shiraishi, G. Nishimura, A. T. Hirai and I. Komasawa, Ind. Eng. Chem. Res., 2002, 41, 5065-5070.

50 E. Repoa, J. K. Warcholc, T. A. Kurniawana and M. E. T. Sillanpää, Chem. Eng. J., 2010, 161, 73-82.
51 M. A. Hughes and E. Rosenberg, Sep. Sci. Technol., 2007, 42, 261-283.

52 G. Y. Li, K. L. Huang, Y. R. Jiang, D. L. Yang and P. Ding, Int. J. Biol. Macromol., 2008, 42, 405-412.

53 F. J. Arriagada and K. J. Osseo-Asare, J. Colloid Interface Sci., 1999, 211, 210-220.

54 J. Liu, Z. Sun, Y. Deng, Y. Zou, C. Li, X. Guo, L. Xiong, Y. Gao, F. Li and D. Zhao, Angew. Chem., Int. Ed., 2009, 48, 58755879.

55 H. Pan, X. Li, D. Zhang, Y. Guan and P. Wu, J. Mol. Catal. A: Chem., 2013, 277, 108-114.

56 S. Sayin and M. Yilmaz, J. Chem. Eng. Data, 2011, 56, 20202029.

57 Z. C. Li, H. T. Fan, Y. Zhang, M. X. Chen, Z. Y. Yu, X. Q. Cao and T. Sun, Chem. Eng. J., 2011, 171, 703-710.

58 H. Chen, C. Deng and X. Zhang, Angew. Chem., Int. Ed., 2010, 49, 607-611.

59 R. Qin, F. Li, M. Chen and W. Jiang, Appl. Surf. Sci., 2009, 256, 27-32.

60 A. I. Frenkel, C. W. Hills and R. G. Nuzzo, J. Phys. Chem. B, 2001, 105, 12689-12703.

61 G. Neri, C. Milone, S. Galvagno, A. P. J. Pijpers and J. Schwank, Appl. Catal., A, 2002, 227, 105-115.

62 R. Nie, D. Liang, L. Shen, J. Gao, P. Chen and Z. Hou, Appl. Catal., B, 2012, 127, 212-220.

63 Z. Yan, Z. Xu, Z. Yang, L. Yue and L. Huang, Appl. Surf. Sci., 2019, 467-468, 277-285.

64 J. Wang, S. Zheng, Y. Shao, J. Liu, Z. Xu and D. Zhu, J. Colloid Interface Sci., 2010, 349, 293-299.

65 F. Ge, M. M. Li, H. Ye and B. X. Zhao, J. Hazard. Mater., 2012, 211-212, 366-372.

66 C. J. Tan and Y. W. Tong, Anal. Chem., 2007, 79, 299-306.

67 D. Peng, Y. Zhang, X. Du, L. Zhang, X. Leng, M. D. Walter and Z. Huang, J. Am. Chem. Soc., 2013, 135, 19154-19166.

68 W. Hu, H. Xie, H. Yue, P. Prinsen and R. Luquee, Catal. Commun., 2017, 97, 51-55.

69 C. C. H. Atienza, T. Diao, K. J. Weller, S. A. Nye, K. M. Lewis, J. G. P. Delis, J. L. Boyer, A. K. Roy and P. J. Chirik, J. Am. Chem. Soc., 2014, 136, 12108-12118.

70 I. Buslov, F. Song and X. Hu, Angew. Chem., Int. Ed., 2016, 55, 12295-12299.

71 A. Vasseur, J. Bruffaerts and I. Marek, Nat. Chem., 2016, 8, 209-219.

72 R. Ciriminna, V. Pandarus, G. Gingras, F. Béland and M. Pagliaro, ACS Sustainable Chem. Eng., 2013, 1, 249-253.

73 E. A. Chernyshev, Z. V. Belyakova, L. K. Knyazeva and N. N. Khromykh, Russ. J. Gen. Chem., 2007, 77, 55-61. 